This article has been retracted: please see INNOVATIONS in pharmacy retraction policy (https://pubs.lib.umn.edu/index.php/innovations/policies). This article has been retracted by the Editor and Publisher due to the inappropriate use of previously published work. 


\title{
Alternative Treatments for Minor GI Ailments
}

AK Mohiuddin, Assistant Professor

Department of Pharmacy, World University of Bangladesh, Bangladesh

\begin{abstract}
About $80 \%$ of the population worldwide use a variety of traditional medicine, including herbal medicines, for the diagnosis, prevention and treatment of illnesses, and for the improvement of general well-being. Total consumer spending on herbal dietary supplements in the United States reached an estimated \$8.085 billion in 2017. In addition, the $8.5 \%$ increase in total sales from 2016 is the strongest growth for these products in more than 15 years. The main reason to use herbal products in these countries is the assumption of a better tolerability compared to synthetic drugs. Whereas in developing countries herbal medicines are mostly the only available and affordable treatment option. Surveys from industrialized countries reveal as main health areas in which herbal products are used for upper airway diseases including cough and common cold; other leading causes are gastrointestinal, nervous and urinary complaints up to painful conditions such as rheumatic diseases, joint pain and stiffness. Gastrointestinal disorders are the most widespread problems in health care. Many factors may upset the Gl tract and its motility (or ability to keep m my n cluding: eating a diet low in fiber; lack of motion or sedentary lifestyle; frequent traveling or changes in daily routine; havir excessive riry products; anxiety and depression; resisting the urge to have a bowel movement habitually or due to pain of hemormoia. misuse o jaxatives (stool softeners) that, over time, weaken the bowel muscles; calcium or aluminum antacids, antidepressap, iron pils, varr cics; pregnancy. About 30\% to $40 \%$ of adults claim to have frequent indigestion, and over 50 million visits are ade g cually tuambulatory care facilities for symptoms related to the digestive system. Over ten million endoscopies and surgi p p cures in olving the GI tract are performed each year. Community-based studies from around the world demonstrate that $0 \%$ to 46, of children meet the criteria for RAP. Gastrointestinal disorders such as chronic or acute diarrhea, malabsorptior, aba vinal pain, and inflammatory bowel diseases can indicate immune deficiency, present in 5\% to 50\% of patients with primaryimmunode iencies. The gastrointestinal tract is the largest lymphoid organ in the body, so it is not surprising that intestin diseases are Common among immunodeficient patients. Gastroenterologists therefore must be able to diagnose and treat p tients wit primary immunodeficiency. Further, pathogens do influence the gut function. On the other hand, dietary habits and spech food typ san play a significant role in the onset, treatment, and prevention of many GI disorders. Many of these can be $p$ anted on by maintaining a healthy lifestyle, and practicing good bowel habits.
\end{abstract}

Keywords: Herbs; Bowel; Gastric Mucosa; Probiotic LCO mic i rden; HRQoL

Purpose of The Study: Review of proper urilizat, foods, herbs and other alternative treatment op ons to prev minor GI
disorders.

Methodology: Comprehep viter are followed by consulting healthcare orofes onals out GI disorders. Hospital, clinic and com, ny newspaper journalists, NGO workers and a few $1 \mathrm{k}$ healers, alternative medicine specialists given their valua suggestions. A few western magazine and newspapers also observed to get the necessary concern. The present study was started from the beginning of 2018. PubMed, ALTAVISTA, Embase, Scopus, Web of Science, and the Cochrane Central Register of was thoroughly searched. The keywords were used to search for different publishers' journals like Elsevier, Springer, Willey Online Library, Wolters Kluwer were extensively followed.

Corresponding author: AK Mohiuddin, Assistant Professor Department of Pharmacy, World University of Bangladesh 151/8, Green Road, Dhanmondi, Dhaka - 1205, Bangladesh Phone: +8801716477485; Email: trymohi@gmail.com
Projections were based on public life pattern, their food habits, contamination sources, different uses of available herbs and daily-consumed foods, their medicinal values in minor GI ailments.

Findings: Conventional treatments unable to prove themselves in Gl disorders more often. Complimentary drugs, probiotics along with food and lifestyle adjustment according to suggested guideline ensures patient satisfaction, improves HRQoL, reduce exacerbation. Further research necessary to both system of medicine to be more trustworthy and to ensure more fruitful outcome in this arena.

Limitation of the study: Lack of recent statistical research data found in this arena of study, however, data obtained from valid sources are added to this article.

Practical Implication: Along with pharmacists, pharmacy students, physicians, nurses and other health workers, policy makers, conscious general people have to assimilate many subject matters from this article. 


\section{Article Highlights:}

1. About $80 \%$ of the population worldwide use a variety of traditional medicine.

2. Sales of HDS in US passed $\$ 8$ billion in 2017 , with $8.5 \%$ increase in total sales from 2016.

3. In community settings, almost $50 \%$ of patients with FGIDs used CAM therapies

4. GERD affects up to $40 \%$ of the population, $40 \%-50 \%$ of patients with GERD have abnormal peristalsis.

5. $20-30 \%$ continue to experience reflux symptoms despite PPI treatment

6. Dyspepsia affects $20 \%$ of the global population, 30 $70 \%$ of the patients with functional dyspepsia experience delayed gastric emptying.

7. Dyspepsia prevalence was $30.4 \%$ in India, $24 \%$ in Spain and $45 \%$ in Nigeria.

8. The prevalence of functional dyspepsia is $12-15 \%$ in patients with IBS.

9. $30 \%$ of the general population experiences constipation during lifetime but incidence sometimes rises up to $80 \%$ in critically ill patients.

10. The economic burden of IBS in the U.S. is estimated at $\$ 28$ billion annually, $32 \%$ of IBS-C patients suffer depression as their condition almost every day in the previous month.

11. Sexual dysfunction is positively associated with perceived GI symptom severity and HRQoL

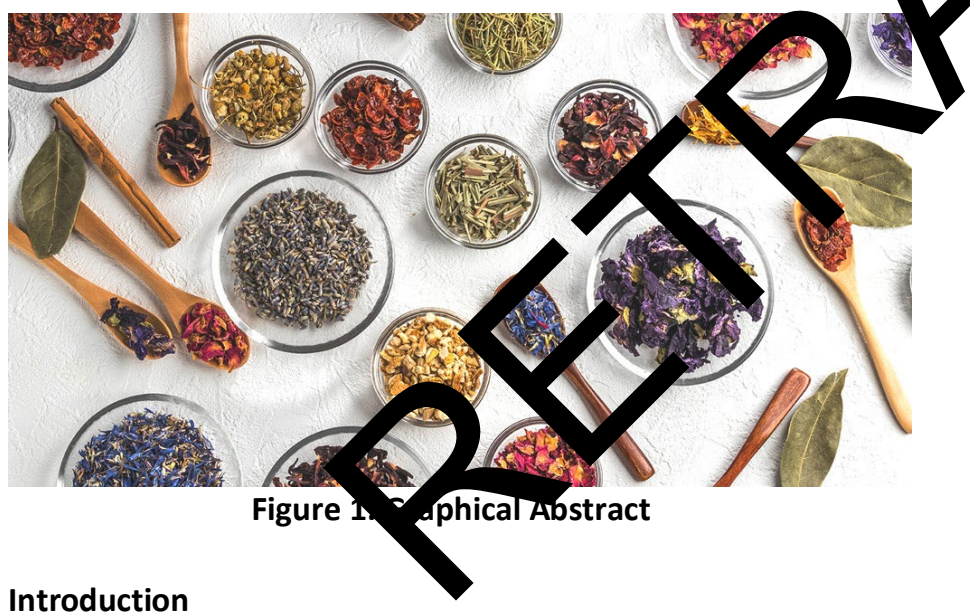

The digestive system is dedicated to breaking down food and allowing its nutrients to be absorbed into the bloodstream, from where they are then carried to every part of the body. Spices and herbal remedies have been used since ancient times to treat a variety of disorders. It has been experimentally demonstrated that spices, herbs, and their extracts possess antimicrobial, anti-inflammatory, antirheumatic, lipidlowering, hepatoprotective, nephroprotective, antimutagenic and anticancer activities, besides their gastroprotective and anti-ulcer activities. Nowadays, several experimental studies and, to a lesser extent, clinical trials have also emphasized the role of herbs in the treatment of a variety of disorders. Several herbs and herbal extracts have been shown to possess antibacterial properties. For instance, onion, garlic, ginger, pepper and mustard have demonstrated antimicrobial activity against several types of bacteria. Tayel and El-Tras have recently reported a potent antibacterial activity of cinnamon and clove against several bacterial strains. Some spices possess antifungal activity. Beside their antifungal activity, herbs have also shown vermicidal, nematocidal and molluscicidal potential. In addition, gingerol, the active ingredient of ginger, and eugenol have shown anti-inflammatory and antirheumatic activity. More recent studies have also demonstrated antiinflammatory and antirheumatic properties of herbs. Furthermore, gingerol and curcumin have also shown lipidlowering potential in experimental animals as well as in clinical trials. The mechanism of epic pain and dyspepsia induced by red and black peppe is not II-defined. However, it is believed to be a consed nnce of in ibition of gastric surface hydrophobicity, e Aancen of surface wettability and activation of in amuce al pareceptors. Some spices may stimulate acin re on andhave deleterious effects on the gastric my osal lin. Intr astric perfusion of albino rats with aqueor tracts oled pepper, fennel, omum/ajwain, cardamom, bl k pepper, cumin and coriander have stimulated crounergic re, onse, and/or via other mechanism(s) have nduced asid secretion with a respectively.

\section{$C, D$}

The AGC guidelines define GERD as "symptoms or complications resuting from the reflux of gastric contents into the esophagus or beyond, into the oral cavity (including larynx) or lung. GERD is one of the most common diseases in society, affecting up to $40 \%$ of the population [22]. A systematic review demonstrated that the prevalence of GERD ranged from $18.1 \%$ to $27.8 \%$ in North America, $8.8 \%$ to $25.9 \%$ in Europe, $2.5 \%$ to $7.8 \%$ in East Asia, $8.7 \%$ to $33.1 \%$ in the Middle East, $11.6 \%$ in Australia, and $23.0 \%$ in South America [1]. The cardinal symptoms of GERD are heartburn and regurgitation. However, GERD may present with a variety of other symptoms, including water brash, chest pain or discomfort, dysphagia, belching, epigastric pain, nausea, and bloating. In addition, patients may experience extraesophageal symptoms like cough, hoarseness, throat clearing, throat pain or burning, wheezing, and sleep disturbances [2]. Approximately $50 \%$ of the patients presenting with heartburn have erosive esophagitis on upper endoscopy, up to $70 \%$ of these patients have normal endoscopy findings. Furthermore, $40 \%$ of those with normal endoscopy findings and normal $\mathrm{pH}$ test results have reflux hypersensitivity (a positive correlation between symptoms and reflux events), and $60 \%$ have functional heartburn [8]. Impaired aspects of quality of life are disturbed sleep, reduced vitality, generalized body pain, unsatisfactory sex life, and anxiety. Nocturnal symptoms caused by reflux appear to have a particularly marked influence on quality of life and the burden of illness imposed by GERD also has an impact on work productivity [23]. Studies have demonstrated that symptom frequency, severity, or combination of both are not predictive of any specific phenotypic presentation of GERD [3]. 
However, elderly patients with GERD appear to experience a more severe mucosal disease that is associated with overall milder and more atypical symptoms [4]. $40 \%-50 \%$ of patients with GERD have abnormal peristalsis. This dysmotility is particularly severe in about $20 \%$ of patients because of very low amplitude of peristalsis and/or abnormal propagation of the peristaltic waves (ineffective esophageal motility) 17]. Other symptoms of GERD include: sore throat; sour taste in the back of the mouth; asthma symptoms (prevalence of GERD found in $30 \%$ to $65 \%$ patients with asthma), dry cough; trouble swallowing $[18,19]$. Psychological comorbidity (anxiety, hypervigilance, depression, and somatization) does play an important role in patients with refractory heartburn [7]. GERD has emerged as a comorbidity of asthma and COPD. The prevalence of GERD in asthma patients has ranged from $25 \%$ to $80 \%, 38 \%$ of asthma patients had GERD in another study [1], [44]. The prevalence of GERD in COPD ranges from $17 \%$ to $78 \%$. Although GERD is usually confined to the lower esophagus in some individuals, it may be associated with pulmonary micro- aspiration of gastric contents [45]. The overall prevalence of IBS symptoms in the GERD population ranges from 10-74\% [64].

\section{Lifestyle Modification for Gastroesophageal Reflux}

Mediterranean (frequent consumption of composite and/or traditional dishes, fresh fruit and vegetables, olive oil, and fish) to a beneficial effect in the occurrence of GERD [24]. Patients with reflux often benefit from a diet that avoids specific food triggers. In particular, fatty foods, spicy foods, acidic foods, chocolate, and caffeine worsen reflux symptoms. Prior to completely eliminating wheat, a celiac screen should be performed with a tissue transglutaminase IgA antibody, and a total IgA level [21]. Even modest weight gain can exacerbate GERD symptoms and womo reduced their BMI by 3.5 units or more reported $40 \%$ re ction in the frequency of GERD symptoms comps with ntrols [5]. Cessation of tobacco, alcohol, $c^{\prime}$ ocolate, affeip or coffee, citrus, mint or spicy food may prove clin or physiological parameters of GERD [6]. Cho in sum stimulates the production of saliva, it helps di fe and ar thr acid from unwanted areas [26].

Exhibit 1. Non-Drug Treatment Options of GERD [10], [20], [30]

\begin{tabular}{|c|c|}
\hline 1. & Elevation of the bed head $(15 \mathrm{~cm})$ \\
\hline 2. & $\begin{array}{l}\text { Moderation in the ingestion of the following food } \\
\text { beverages, mint, peppermint, tomato, chocolate }\end{array}$ \\
\hline 3. & $\begin{array}{l}\text { Refraining from wearing tight-fitting clothes: Cloth } \\
\text { pressure can then affect the LES, increasing reflux. }\end{array}$ \\
\hline 4. & Avoidance of lying down in the $2 \mathrm{~h}$ follov \\
\hline 5. & $\begin{array}{l}\text { Eliminate distractions at mealtime. Avoi } \\
\text { smaller meals rather than big meals. Ov }\end{array}$ \\
\hline 6. & Quitting of smoking \\
\hline 7. & Reduction of body weight, if \\
\hline
\end{tabular}

\section{GERD Expenditure}

GERD is a common, chronic, rela po pmptom. Often people self-diagnose and self-tre evo tho health-related quality of life is signifig atly in paired. the lack of a valid alternative approach, ca rent ts focus on suppression of gastric acid secretion D the use of PPIs, but people with GERD have a significantly low response rate to therapy [9], approximately 20-30\% continue to experience reflux symptoms despite PPI treatment [11]. 30-40\% of patients receiving medical therapy with PPIs experience troublesome breakthrough symptoms, and recent evidence suggests that this therapy is related to increased risk of complications [12]. In the US alone, overall spending on all GI diseases is estimated to be \$142 billion (in 2009 US dollars) per year in direct and indirect costs. GERD accounts for approximately $\$ 15-20$ billion of these direct and indirect costs. It has been estimated that prescribed medications for GERD, primarily PPIs, account for over $50 \%$ of prescriptions for all digestive diseases, resulting in around $\$ 10$ billion in annual direct health care costs $[25,26]$. Extraesophageal manifestations of reflux, including LPR, asthma, and chronic cough, have been estimated to cost $\$ 5438$ per patient in direct medical expenses in the first year after presentation and $\$ 13,700$ for 5 years [28].

\section{Herbs for GERD Management}

Some research has also shown improved symptoms in people with GERD who take peppermint oil. Historically, ginger has been used to treat other gastrointestinal ailments, including heartburn. This may reduce overall swelling and irritation in the esophagus. Caraway, garden angelica, German chamomile flower, greater celandine, licorice root, lemon balm, milk thistle and turmeric have little clinical evidence to support their effectiveness [29]. Fermented foods, like kimchi (alkaline), can be incredibly helpful for digestive system. Consuming a spoonful of mustard during the onset of acid reflux symptoms of heartburn by balancing $\mathrm{pH}$ levels. Many patients have seen significant benefits from snacking tasty nuts (especially almond), to be consumed raw, organic and salt-free. Both bananas and apples contain natural antacids that can help relieve or prevent an onset of acid reflux [26]. Marshmallow (Althea officinalis L.) contains a mucilage quality (may interfere with the absorption of other medications) which helps to coat 
the esophagus and stomach lining, creating a protective barrier against stomach acid. It's an effective stimulator of cell physiology of epithelial cells which can prove the traditional use of Marshmallow preparations for treatment of irritated mucous membranes within tissue regeneration [31,32]. Chewing DGL (deglycyrrhizinated licorice) also helps boost enzyme production, allowing for easier and quicker digestion as well as better absorption of nutrients [32]. Use of low doses of pure glycyrrhetinic acid and bilberry anthocyanosides, together with alginic acid as addon therapy, substantially improves symptoms in patients with nonerosive reflux disease without increasing side effects or worsening tolerability or compliance [33]. To add to all that nutrition, papaya is an excellent treatment for acid reflux. It contains a proteolytic enzyme that breaks down proteins in the digestive system into amino acids. The active ingredient, papaine, is helpful to the digestion of fats and carbs. It aids in digestion and allows body to make acid. The potassium in papaya (Carica papaya L.) also introduces healthy bacteria into intestines. This can prevent stomach from working as hard and helps to stop indigestion and reflux. Papaya is used as a natural remedy in abnormal digestion in tropical and industrialized countries [34-36]. The fenugreek fiber effects were generally similar to the results produced by an OTC antacid medication (ranitidine at $75 \mathrm{mg}$, twice a day). 2 weeks intake of a fenugreek fiber product, taken 30 min before two meals/day, diminished heartburn severity [37]. Tho cytoprotective effect of the seeds seemed to be not only due the anti-secretory action but also to the effects on mucosal glycoproteins. The fenugreek seeds also prevented lipid peroxidation induced by ethanol presumably antioxidant potential of the gastric mucosa mucosal injury. Histological studies reveale that th soluble gel fraction derived from the seeds wa no effectiv than omeprazole in preventing lesion formath [38]. An involvement of Opuntia ficus dica mucilago (mainly cultivated in the Mediterranean gion $d$ in Central America) has been hypothesized, mainly for by ara mogalactan and galacturonic acid, forn ig de ps layer in these gastroprotective effect the $m$, cilage is trongly viscous which because of the negative ses causes strong intermolecular repulsion, resulting in expan on of the molecules. It is believed that this changing in molecula shape could be responsible for the protection of the gastric mucosa [13-15]. Olive leaf extract possesses antioxidant properties, which can positively influence gastroprotection. The main iridoide monoterpene oleuropein contained in olive leaf was usually thought to be responsible for pharmacological effects but it was recently observed that olive leaf is as a stable source of bioactive flavonoids. In fact, the contribution of flavonoids to the overall radical scavenging activity of olive leaf extracts has been investigated and luteolin 7-O-glucoside was found to be one of the dominant scavengers (8-25\%) [16]. Turmeric (Curcuma longa) and its compounds (especially Curcumin) should be considered as a promising alternative for patients who suffer from digestive disorders because it is safe, inexpensive, and ubiquitously available. Curcumin has been defined as the most active component in $\mathrm{C}$. longa and has considerable gastroprotective and antiulcerogenic effect. Improvement in clinical scores of GERD and GERD Activity Index is proven with turmeric $[39,40]$. German chamomile (Matricaria recutita) (contains flavonoids, in particular apigeningastric shown protective effect in clinical trial) and bismuth have known gastric protective properties, and Atropa belladonna contains anticholinergic agents that have bronchodilatory effect. Complementary treatments containing these ingredients could be used to treat patient with asthma patients having GERD, and if effective, could be an additional treatment tool that could also reduce the use of long-term inhaled corticosteroids and proton pump inhibitor trea and the their side effects [41]. Although a number toxic ects have been attributed to bismuth compows in pumans: nephropathy, encephalopathy, ceoarth pathy gingivitis, stomatitis and colitis. Whether cepatit is a effect, however, is open to dispute [42].Alo Ver was safe and well tolerated and reduced the frequ Mies o all th assessed GERD symptoms, but nephre $x$ ty and hatoxicity (also human carcinogen, Group 2B) is k ping its use in a controversial position [46-49]. Pyspepsia Dyspepsia s common, affecting approximately $20 \%$ of the g. val $\mathrm{p}$ culation, and is frequently encountered in primary care. Functional dyspepsia (FD) is one of the most prevalent gas rointestinal disorders, and is defined as a chronic disease with persistent upper gastrointestinal symptoms without any explanatory organic or metabolic causes [50]. Dyspepsia is a very common $\mathrm{Gl}$ complaint, with up to one in five individuals affected worldwide. Of those with dyspepsia, around $40 \%$ will seek the advice of their primary care physician. Almost $15 \%$ of patients with dyspepsia are referred to secondary care for further investigation and management [58]. When broadly defined, dyspepsia occurs in $40 \%$, leads to GP consultation in $5 \%$ and referral for endoscopy in $1 \%$ of the population annually. In patients with signs or symptoms severe enough to merit endoscopy, $40 \%$ have functional or non-ulcer dyspepsia, $40 \%$ have GERD and $13 \%$ have some form of ulcer [62]. Heartburn and acid regurgitation are no longer considered to be symptoms of dyspepsia, but of GER. Both the underlying causes and progress of functional dyspepsia are still unknown. That is largely true of GERD as well [65]. One-third of patients who visit general physician practices are patients with dyspepsia syndrome; and half of patients who visit gastroenterologists are also patients with dyspepsia syndrome [66]. The prevalence of functional dyspepsia was UK (21\%), US (26\%), Jordan (60\%), western Iran (18\%), China (18.4\%) found in a 2014 study [51]. In a German study, around one third of the normal persons interviewed reported dyspeptic symptoms, including acute dyspepsia in $6.5 \%$ and chronic dyspepsia in $22.5 \%$ of cases [52]. $8 \%-30 \%$ and $8 \%-23 \%$ of Asian people suffer from of uninvestigated dyspepsia and FD, respectively [53]. Dyspepsia prevalence was $30.4 \%$ in India, $5 \%$ in Scandinavian countries, 
$24 \%$ in Spain and $45 \%$ in Nigeria estimated [68]. Smoking might affect all gastrointestinal functions including those of the esophagus, stomach, and colon, resulting in susceptibility to several kinds of FGIDs including GERD, FD, and IBS [54]. Potential lifestyle factors associated with dyspepsia include tobacco, alcohol, and analgesic consumption. Furthermore, dietary habits that include consumption of smoked food, fast food, salty food, coffee/tea, and spicy food were associated with aggravating the symptoms of dyspepsia; while fruits, vegetables, and water were noted to improve the symptoms [68]. FD is more prevalent in women (24.4\%) than men (16.6\%) and its occurrence was found to increase significantly with age $[69,70]$. Typical dyspeptic symptoms include postprandial fullness, early satiety, epigastric pain, and epigastric burning [55]. Visceral hypersensitivity, impaired gastric accommodation and impaired gastric emptying are commonly reported by patients with functional dyspepsia. Involvement of duodenal hypersensitivity to the luminal contents, small bowel dysmotility, psychological disturbances, central nervous system disorders and Helicobacter pylori infection also been reported [56]. Delayed gastric emptying has been reported by gastric scintigraphy in a large proportion (up to $45 \%$ ) of dyspeptic patients, especially those with PDS [57]. About $30-70 \%$ of the patients with functional dyspepsia experience delayed gastric emptying [86]. The overall costs to the health service associated with managing dyspepsia are considerable, estimated to be over $\$ 18$ billion per annum in the United States. Moreover, when one considers that dyspepsia impacts on physical, mental, and social aspects of health-related quality of life, the true overall costs to society are likely to be far higher, and also encompass loss of economic productivity due to sicknessrelated absence from work [58-60]. The risk of malignancy predominantly relates to ing age, and so guidelines have previously recommende upper endoscopy to routinely investigate dyspepsia on, when pat hts are aged 55 years and older [61]. The prey rence o unctic al dyspepsia (after normal upper endoscop, is $12,5 \%$ in ants with IBS [64].

Exhibit 2. Alarm features in patients wit' aty opsia [61]

- Age $>55$ years with new onset dyspepsia*

- Evidence of overt gastrointestinal bleeding including melaep -rmatemes

- Dysphagia, particularly if progressive, and odynophagia

- Persistent vomiting

- Unintentional weight loss

- Palpable abdominal or epigastric mass or abnorm

- Family history of upper gastrointestinal cancer

- Evidence of iron deficiency anemia after blond testi

* ACG/CAG guidelines now recommend an age ${ }^{t}$ esh y of 6 years or older.

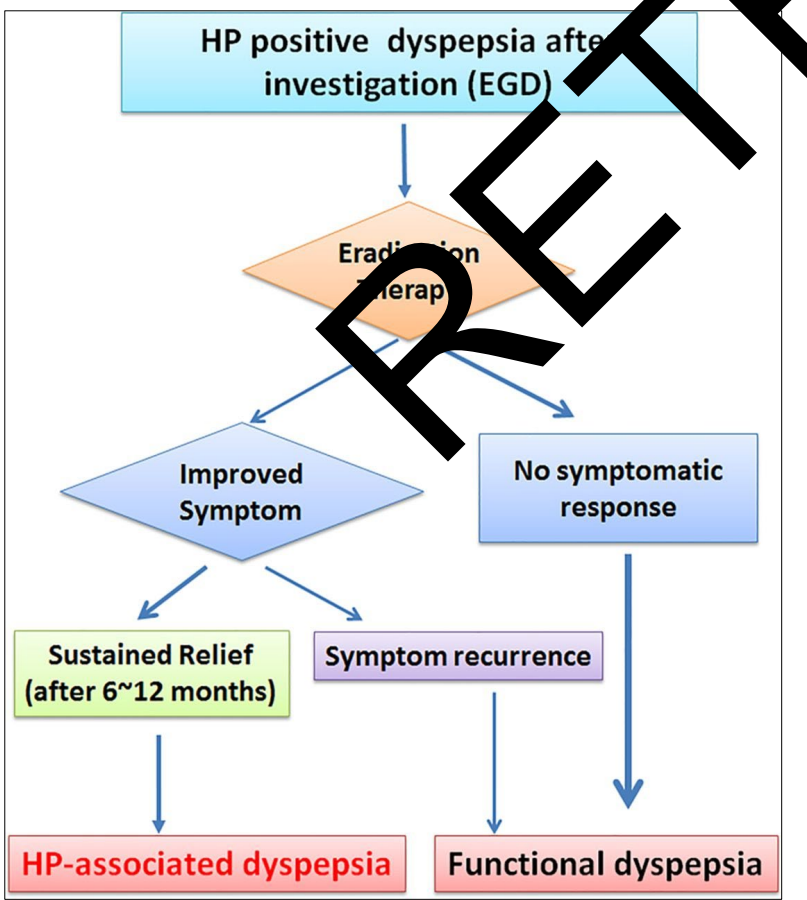

Figure 2

Figure 2. Diagnostic algorithm of Helicobacter pylori-associated dyspepsia. Patients with dyspeptic symptoms after negative routine laboratory and upper gastrointestinal endoscopy except for positive H. pylori tests, should undergo eradication therapy. If sustained symptomatic relief is obtained, their dyspeptic symptoms are considered as $\mathrm{H}$. pylori-associated dyspepsia. On the other hand, if dyspeptic symptoms do not resolve or recur after eradication therapy, they are judged to have functional dyspepsia. EGD, oesophagastroduodenoscopy (Source: Sugano K, Tack J, Kuipers EJ on behalf of faculty members of Kyoto Global Consensus Conference, et al Kyoto global consensus report on Helicobacter pylori gastritis Gut 2015;64:1353-1367). 


\section{Rationale of Alternative Treatments with Dyspepsia}

Prokinetics are recommended for the treatment of functional dyspepsia (FD) but systematic reviews give conflicting results on the efficacy of these agents [62]. Although several PPI-related adverse effects have been reported, their clinical relevance is not yet clear. Again, their beneficial effects for functional dyspepsia have not been fully confirmed [63]. The popularity of CAM in treating FGIDs has steadily increased in Western countries. In community settings, almost $50 \%$ of patients with
FGIDs used CAM therapies. Herbal remedies consist of multicomponent preparations, whose mechanisms of action have not been systematically clarified. Few studies analyzed the effectiveness of acupuncture in Western countries, yielding conflicting results and possibly reflecting a population bias of this treatment. Hypnosis has been extensively used in irritable bowel syndrome, but few data support its role in treating FD [67].

\begin{tabular}{|c|c|}
\hline Adverse events unrelated to acid inhibition & Adverse events related to acid inhibition \\
\hline Allergic reaction to drug chemicals & Pneumonia \\
\hline Collagenous colitis & Gastrointestinal infection \\
\hline Acute interstitial nephritis & Gastric carcinoid tumor \\
\hline Chronic kidney disease & Gastric fundic mucc \\
\hline Drug interaction & Changes in gut mic \\
\hline Dementia & Small intestinal ba \\
\hline Cerebral ischemic diseases & Iron deficiency \\
\hline Ischemic cardiac diseases & $\begin{array}{l}\text { Bone fracture-ancrease cal 'm absorption; Vitamin B12 deficiency; } \\
\text { Hypomagn semia; Gastric funtric gland polyps; Gastric \& Colon cancer; } \\
\text { Spontane Us bacteria eritonitis; Hepatic encephalopathy; Drug interaction }\end{array}$ \\
\hline
\end{tabular}

\section{Herbs and Probiotics for Dyspepsia}

Flavonoid rich phytochemical composition of the root extract 0 Glycyrrhiza glabra, revealed significant decrease in scores of dyspepsia [71]. Adjuvant supplementati based formulation of Black Seed/ black caraway can cause significant symptomatic improve ent batients with functional dyspepsia whom receiver standa antisecretory therapy [72]. Basil Leaf (ocimu basilicum L) strengthens stomach, nervous syste and is also rminative, also has been demonstrated tocre acid and pepsin outputs, widely used as a spice a pical ingredient of the healthy Mediterranean 73,15 fruit of Amla (Phyllanthus emblica has cytop ctive acid-reducing features, prevents ind stio nellols acidity and well tolerated [75-77]. Pistacia nticus Desf. (Mastaki) act against different microorganisms (M. tic gum) specially Helicobacter pylori, positively affect liver function, could be effective as an alternative regime in patients unwilling to undergo eradication with the triple therapy regime $[78,79]$. Rhizome of Ginger (Zingiber officinale Roscoe) is stomach tonic, protective, antiulcer and is effective for digestion problems, bloating, and nausea, stimulated gastric emptying and antral contractions in patients with functional dyspepsia [80-83]. Iberogast (commercial preparation of 9 herbal extracts including bitter candy tuft, lemon balm leaf, chamomile flower, caraway fruit, licorice root, angelica root, milk thistle fruit, peppermint leaf, and greater celandine herb) has been shown to protect against the development of ulcers with decreased acid production, increased mucin production, an increase in prostaglandin E2 release, both safe and effective for treatment of functional dys ad and IBS in Children [21]. Licorice root, the dried izome or extracts of glycyrrhiza glabra, has long been used in botanical medicine for treatment of gastric inflammation, showed a significant decrease in total symptom scores $(p<$ 0.05 ) and improvement in quality of life with functional dyspepsia [77]. Red pepper as a drug is given in atonic dyspepsia and flatulence due to increasing the motility in the gastric antrum, duodenum, proximal jejunum and colon. It can also increase parietal, pepsin, and bile acid secretions. Chilies are known to protect against gastrointestinal ailments including dyspepsia, loss of appetite, gastroesophageal reflux disease and gastric ulcer due to the several mechanisms such as reducing the food transition time through the gastrointestinal tract and anti-Helico pylori effects [85]. Celery (Apiumgraveolens), radish (Raphinussativus L.), rocket (Eruka sativa), and marjoram (Origanummajorana L.) demonstrated anti-ulcer effect in experimental investigations [86]. Probiotics appear effective in the treatment of FD through the normalization of gastric microbiota. The finding of an FD-type phylum profile can be used to characterize patients with FD and may serve as an objective biomarker for both the diagnosis and treatment of FD. Probiotics could be effective treatment for the indigestion via the reduction of Escherichia/Shigella, major source of toxic lipopolysaccharides in the upper GIT [98].

\footnotetext{
Constipation

Constipation is a common gastrointestinal problem, which causes many expenses for the community with an estimated prevalence of $1 \%$ to $80 \%$, worldwide. Various factors are involved in the pathogenesis of the disease, including type of
} 
diet, genetic predisposition, colonic motility, absorption, social economic status, daily behaviors, and biological and pharmaceutical factors. Acute constipation may cause closure of the intestine, which may even require surgery. Chronic constipation is a complicated condition among older individuals, which is characterized by difficult stool passage [87]. To better characterize the condition, physicians conceive constipation objectively using defecation frequency, with a normal range of between three and 21 bowel movements per week [94]. Factors that may contribute to functional constipation include pain, fever, dehydration, dietary and fluid intake, psychological issues, toilet training, medicines, and family history of constipation [88]. Pathogenesis is multifactorial with focusing on the type of diet, genetic predisposition, colonic motility, and absorption, as well as behavioral, biological, and pharmaceutical factors. Furthermore, low fiber dietary intake, inadequate water intake, sedentary lifestyle, IBS, failure to respond to urge to defecate, and slow transit have been revealed to be associated with predisposition $[87,90]$. About $30 \%$ of the general population experiences problems with constipation during life time. with elderly people and women being mostly affected. Constipation is also reported to occur in $2 \%$ to $25 \%$ of healthy people, but the incidence sometimes rises to $80 \%$ in critically ill patients [101].

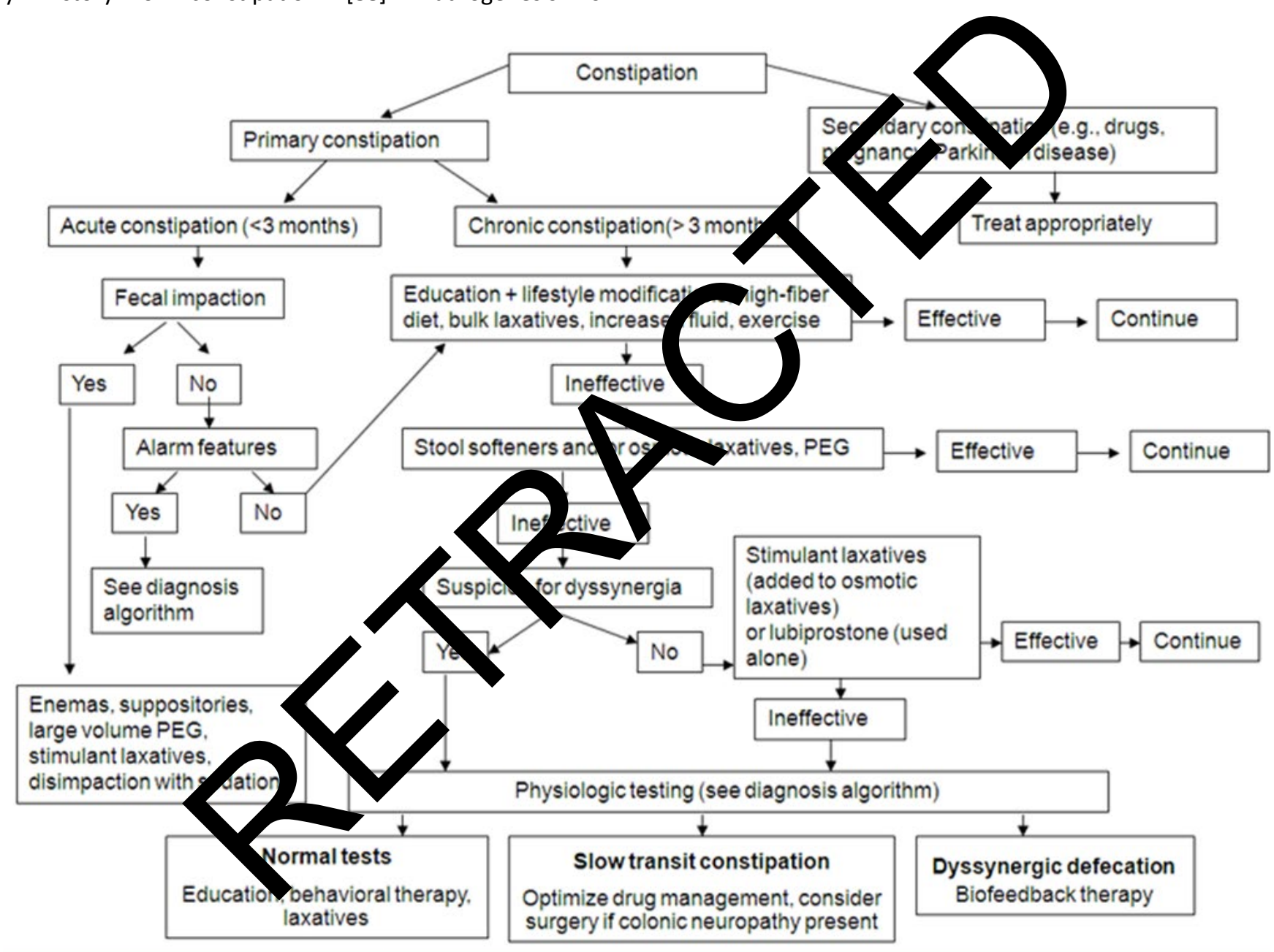

Figure 3. Initial management of acute primary constipation (symptoms $<3$ months) (Source: Constipation in adults: Treatment Practice. BMJ Best Practice). When constipation presents acutely, it is important to consider possible secondary causes, including colorectal cancer. Further investigations may be performed to exclude secondary causes. Enemas, suppositories, large volume polyethylene glycol solution (PEG), stimulant laxatives, or disimpaction with sedation may be required if there is fecal impaction. If fecal impaction is absent and secondary causes are excluded, the treatment is the same as for patients with chronic constipation. Initial steps in the management of chronic primary constipation are: Patient education; Lifestyle modifications; High-fiber diet; Increased fluid; Regular exercise; Bulk laxatives. Dietary and lifestyle changes may be helpful. Patients are advised to increase their daily dietary fiber and calorie intake (in patients with low caloric intake). Patients are advised on adequate fluid intake and encouraged to get regular nonstrenuous exercise. Modest exercise can help relieve constipation, especially if patients are sedentary or generally inactive. Patients are advised to dedicate time for bowel movements and to avoid postponing bowel movements when an urge for defecation is felt. 
Exhibit 4. Common causes of secondary constipation [90]

\begin{tabular}{|c|c|}
\hline |Drugs & $\begin{array}{l}\text { Anabolic steroids, analgesics, opioids (codeine), NSAIDs, anticholinergics, anticonvulsivants, antidepressants, } \\
\text { antihistamines, antihypertensives (verapamil e clonidine), anti-Parkinsonian, diuretics, antiacids containing calcium or } \\
\text { alluminium, cholestyramine. }\end{array}$ \\
\hline$\| \begin{array}{l}\text { Neuropathic and } \\
\text { myopathic disorders }\end{array}$ & \begin{tabular}{|l} 
Amyloidosis, Chagas disease, connective tissue disorders, CNS lesions, autonomic diabetic neuropathy, Hirschprung's \\
disease, multiple sclerosis.
\end{tabular} \\
\hline |ldiopathic & $\begin{array}{l}\text { Paraneoplastic syndromes, Parkinson's disease, dementia, scleroderma, post-viral colon-paresis, intestinal pseudo- } \\
\text { obstruction, spinal or ganglion tumor, ischemia. }\end{array}$ \\
\hline \begin{tabular}{|l} 
Electrolytic balance \\
alterations
\end{tabular} & Hypokalemia, hypercalcemia \\
\hline \multirow{2}{*}{$\begin{array}{l}\text { Organic intestinal } \\
\text { diseases }\end{array}$} & $\begin{array}{l}\text { Obstruction/stenosis: adenoma, cancer, diverticolitis, rectocele, hernia, foreign bodies, faecal impaction, IBD and } \\
\text { complications. }\end{array}$ \\
\hline & Anorectal abnormalities: anal stenosis or fissures, proctitis, rectocele, haemorrhoid \\
\hline $\begin{array}{l}\text { Endocrine-metabolic } \\
\text { causes }\end{array}$ & 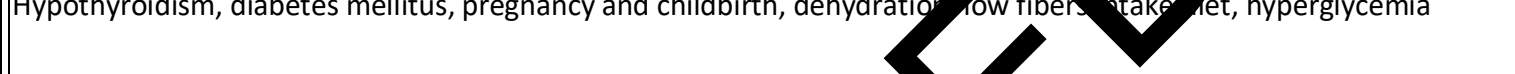 \\
\hline
\end{tabular}

\section{Prevalence and Economic Burden}

Functional constipation is a prevalent condition in childhood, about $29.6 \%$ worldwide. Up to $84 \%$ of functionally constipated children suffer from fecal incontinence, while more than onethird of children present with behavioral problems primary or secondary due to constipation [88]. However, only a minority of patients (approximately $25 \%$ ) uses medical treatmen whereas a considerable proportion relies on alternative solutions, following advices given in pharmacies or shops [91,92]. A population-based study of outpatie emergency department visits found outpatients more drugs had an $88 \%$ increased risk of expen cing an adverse drug effect compared to those w takin ere drugs [93]. According to reports from wester sountries, the prevalence of CC in the general por ation range rom $2 \%$ to $28 \%$, with an increasing trend ar ye 3 . Moreover, severe constipation is frequently obsen $/ /$ eldery women, with rates of 2 to 3 times higher hat thei rale counterparts [95]. FGIDs, including cb onic cl stipat (CC), are among the most frequent illness se astroenterologists and account for up to one-ha of patient care time (1). CC is a remarkably common and cos condition that can negatively impact the QoL, and result in a major social and economic burden [96]. 66,287 people in the UK were admitted to hospital with constipation as the main condition in 2014/15, equivalent to 182 people a day. 48,409 were unplanned e emergency admissions (this is equivalent to 133 per day). The total cost to hospitals for treating unplanned admissions due to constipation was $f 145$ million in $2014 / 15$. The figure is likely to be much higher for total NHS expenditure on constipation when including GP visits, home visits and prescriptions. The prescription cost of laxative costs is $£ 101$ million (Over the counter costs of laxatives will undoubtedly be higher). 1 in 7 adults are affected by constipation at any one time in UK [97]. Pregnancy predisposes women to developing constipation owing to physiologic and anatomic changes in the gastroin inal track instance, rising progesterone levels duringregn cy and reduced motilin hormone levels lead to in in bo transit time. Also, there is increased water bsorption from the intestines, which causes stool to dry out. becreased maternal activity and increased vitamin spleme ation (eg, iron and calcium) can further contribute to converpation. Later in pregnancy, an enlarging uterus might onward movement of feces. Constipation can result in serious complications such as fecal impaction, but such complications are rare [107].

\section{Herbs and Probiotics for Constipation}

Cascara sagrada used (hydroxyanthraquinone glycosides found in the dried bark) to be approved by the U.S. FDA as an OTC drug for constipation. However, over the years, concerns were raised about its safety and effectiveness (causes nausea, vomiting and griping abdominal pain) [98-100]. Psyllium is the most commonly used bulking agent in Canada. In placebocontrol trials, psyllium has been shown to decrease stool transit time, and improve stool frequency, consistency and weight; when psyllium was compared with lactulose, the magnitude of effects on stool frequency was similar, associated benefit of dietary fiber in reducing coronary heart disease and lowering low-density lipoprotein cholesterol, it is generally recommended as the initial conservative treatment for chronic constipation [100]. Recently, maintenance of intestinal motility has become an important issue in intensive-care medicine. Although drugs such as metoclopramide, erythromycin, neostigmine, and others are reported to resolve incompetent intestinal motility [101], there are problems with drug tolerance. Rhubarb has been widely used as a traditional Chinese herbal medicine since ancient times. Sennoside A and other dianthrone derivatives are reported to be the active ingredients causing rhubarb's laxative effect. To induce its laxative effect, rhubarb needs to be metabolized to rhein anthrone by $\beta$-glucosidase, which is produced by gut microbiota 
[102]. Improvement in intestinal motility can prevent sepsis of gut origin [103]. Rhubarb contains dianthrone glucosides (sennosides $A$ to $F$ ) and anthraquinones (e.g., rhein, aloeemodin, emodin, physcion, chrysophanol); Among these components, sennosides (i.e., stimulant laxatives), have been well documented for their pharmacological action on constipation [104]. Senna is used to treat constipation and clear the bowel before some medical procedures.it should only be used in the short term and at the recommended doses. Longterm and high-dose use has been reported to cause liver damage [105]. Senna induced dermatitis is rare, but may occur when patients need a higher dose. Pediatric caregivers should advise families of the rare side effect of skin blistering and educate them to change the diaper frequently in children who are not toilet- trained to reduce stool to skin exposure. Senna is a safe treatment option for constipation in children [106]. Until more data are available, the use of probiotics for the treatment of constipation should be considered investigational. Current ESPGHAN/NASPGHAN recommendations that probiotics should not be used in the treatment of functional constipation in children [113]. The bacterial endotoxin lipopolysaccharide may influence intestinal motility by delaying gastric emptying and inducing sphincteric dysfunction. Human colonic gases produced by microflora may also be associated with changes in gut motility. For example, breath methane excretion in patients with slow-transit constipation was greater than in healthy subjects or patients with normal-transit constipation, supporting the idea that methane can slow gut transit. Collectively, the altered in microbiota may play an essential role in the path senesis o hronic constipation [114].

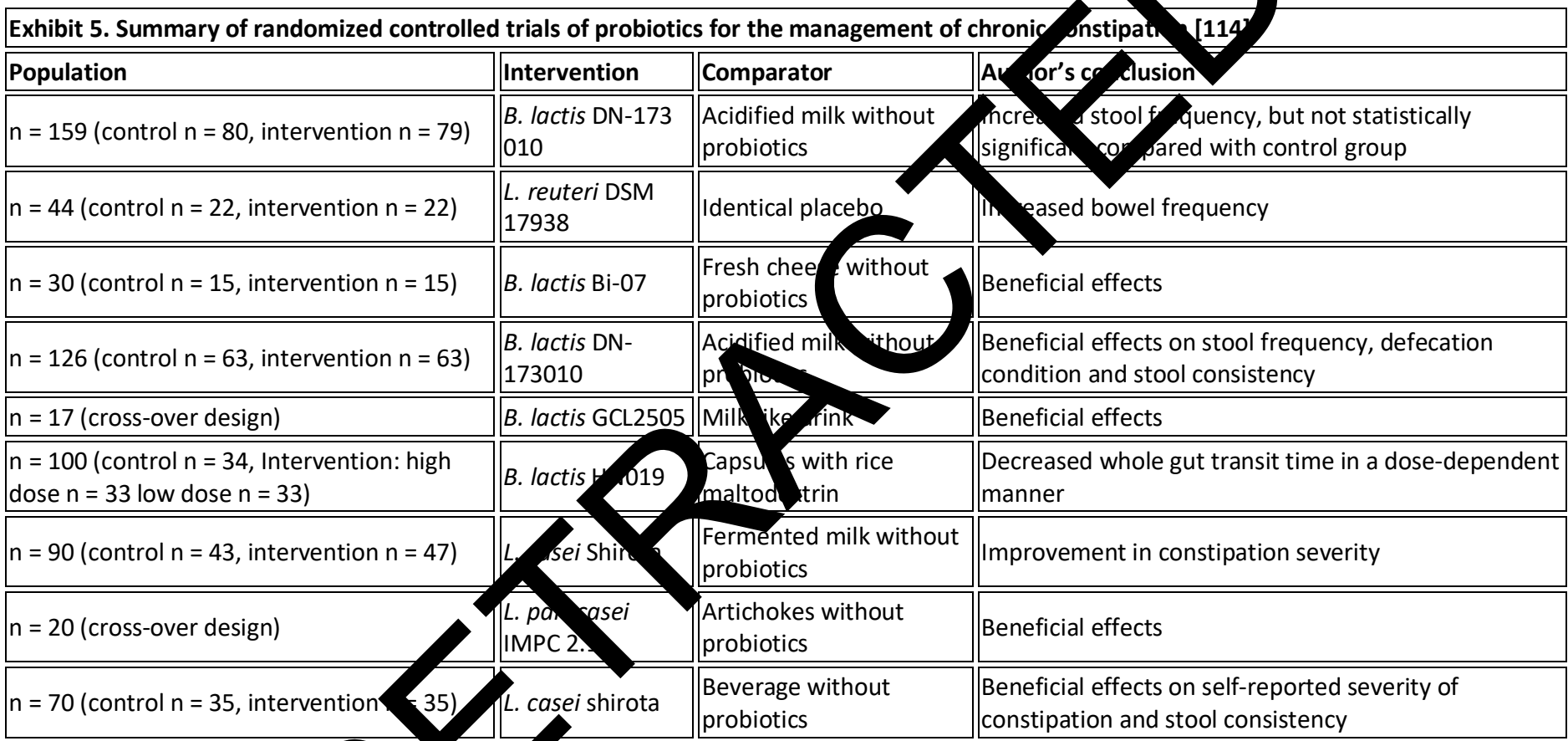

\section{Herbs in Pregnancy Ind ed Co stipatio}

It has been estimated hat appromately $11 \%$ to $38 \%$ of pregnant women experien constipation, which is generally described as infrequent byel movements or difficult evacuation [107]. The prevalence of herbal medicine utilization in pregnancy ranges between $7 \%$ and $55 \%$ in different geographical, social and cultural settings, and ethnic groups [108]. The majority of the studies reported the highest use of herbs during the first trimester with the frequency varying from $17.3 \%$ to $67.5 \%$ in Middle East [107]. It is a well-documented fact that the risk in pregnancy is unknown for $91.2 \%$ of the approved medications. The use of herbal products which are not usually tested in clinical trials during pregnancy could result in immense risk to the mother and fetus $[109,110]$. Since herbal medicines are a part of traditional medicine, they are not included in the FDA pregnancy categories giving a false impression of safety. The whole extracts of these herbal drugs contain numerous active molecules that could elicit adverse effects including teratogenicity $[111,112]$.

\section{Irritable Bowel Syndrome (IBS)}

IBS is present in patients with symptoms of chronic abdominal pain and altered bowel habits but no identifiable organic etiology [113]. Patients with IBS often associate their symptoms to certain foods [115]. In CSID, recessive mutations in the SI gene (coding for the disaccharidase digesting sucrose and $60 \%$ of dietary starch) cause clinical features of IBS through colonic accumulation of undigested carbohydrates, triggering bowel symptoms [116]. Diagnosing IBS can be challenging due to the nonspecific nature of symptoms, overlapping upper and lower abdominal symptoms, and the frequent presence of somatic and psychological comorbidities. Despite these guidelines, there remains low awareness and little consensus on the use of diagnostic tests and surgical procedures in IBS. Furthermore, although surgery has no role in the recommended treatment 
approach for IBS, multiple studies have reported that this patient population is predisposed to unnecessary surgical procedures, suggesting a disconnect between the recommended best practices and real-world management of IBS [117]. Under certain ambiguous circumstances, an exclusive and pure diagnosis of IBS cannot be achieved because of fooddependent symptoms: in fact, up to $80 \%$ of IBS patients identify food as a possible trigger for their symptoms, so they increasingly ask for dietary and behavioral counseling [118]. Common practices for IBS management begin with diet and lifestyle modification, and in more severe cases, pharmacotherapy (e.g. antidepressants, smooth muscle antispasmodics, or secretagogues) [119].

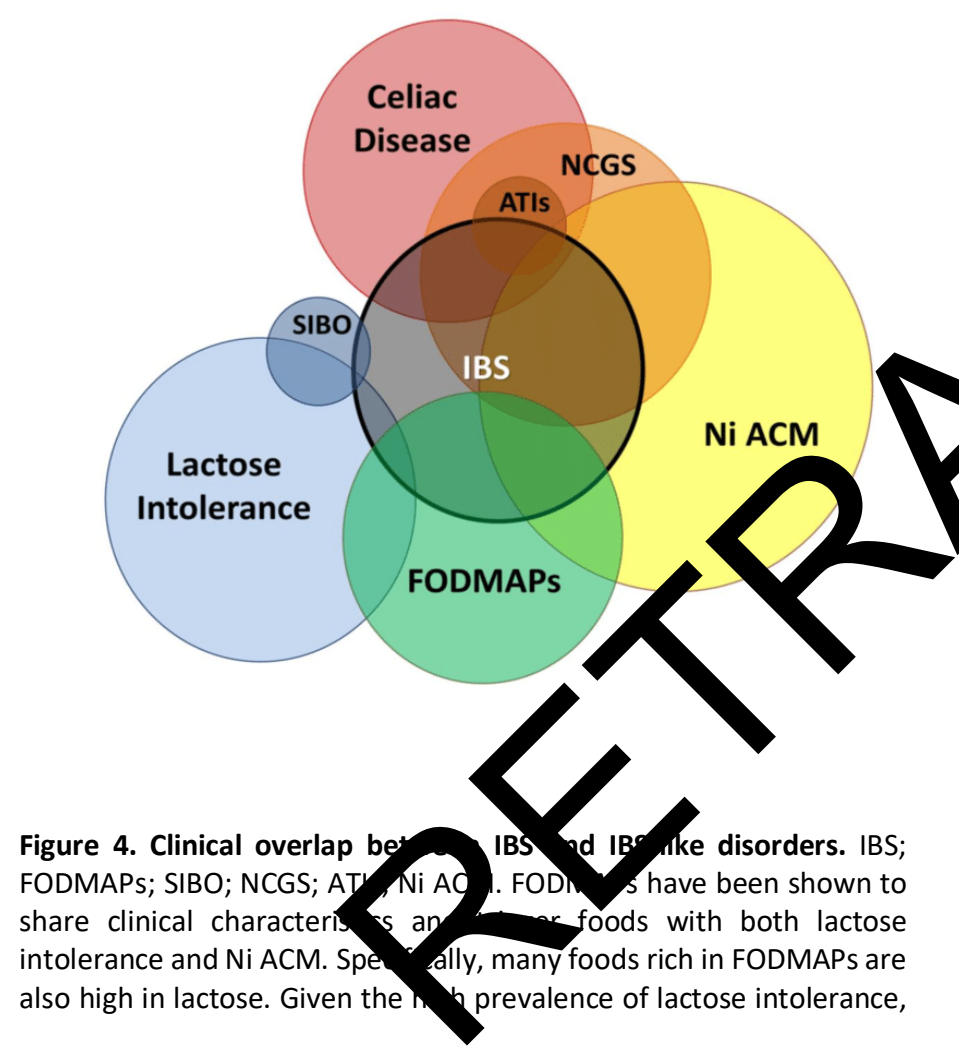

it is not surprising that a diet low in FODMAPs may reduce or even resolve gastrointestinal and extra-intestinal symptoms. The same thing can be true for foods rich in $\mathrm{Ni}$, very numerous in the FODMAPs family, such as pears, cabbage, garlic, onion and legumes. Another important intersection exists between FODMAPs and NCGS, or even better between Ni ACM and NCGS: upon closer analysis, symptoms of suspected NCGS patients are actually triggered by associated Ni-rich ingredients or condiments (e.g. yeast or tomato), and not by gluten itself. As a consequence, foods such as bread, pasta with tomato sauce, pizza and bakery products turn into real traps for $\mathrm{Ni}$-sensitive and/or lactose intolerant patients, in defiance of the Mediterranean diet, recently declared part of the UNESCO's Intangible Heritage List.

\section{Prevalence and Economic Burden}

IBS affects both men and woman of all ages. It is thought only a fraction of individuals w sym oms of IBS seek medical attention. The prevalen of IBS glo ally is $11 \%$, however, it is thought that IBS $\mathrm{ch}$ rel. ins un erdiagnosed. A survey of patients with IB' (both yith without a formal diagnosis) conducted by Ga cointestinal Society in Canada showed that $46 \%$ b miss work school due to IBS symptoms [120]. Its est a d preva is 10\%-20\%, although marked variation $\mathrm{mo}_{0}$ exist based on geographical location; for me, its pre lence is $21 \%$ in South America versus $7 \%$ in outheast Asia. It is nearly twice more common in women than nen [118. Various studies have reported prevalence to be roxim ely 8 to $12 \%$ in children, and 5 to $17 \%$ in adolescents [125]. is causes a significant burden on healthcare systems, an part to the high level of HRU associated with IBS. Direct medical costs attributed to IBS in the US, excluding prescription and OTC medicines, were estimated at US \$1.5-\$10 billion per year in 2005. According to University at Buffalo, the economic burden of IBS in the U.S. is estimated at \$28 billion annually [124]. A portion of these costs may be related to unnecessary and high-frequency tests, although few studies have assessed the factors underlying frequent tests and procedures among patients with IBS [117]. In IBS, it has been reported that $50 \%$ to $90 \%$ of patients have or had at some point one or more common psychiatric condition, including major depressive disorder, generalized anxiety disorder, social phobia, somatization disorder, or posttraumatic stress disorder [123]. 


\begin{tabular}{|c|c|}
\hline IBS-C & $\begin{array}{l}\text { With predominant constipation. The symptoms most frequently reported for IBS-C are: abdominal pain, bloating } \\
\text { and constipation. } 32 \% \text { of IBS-C respondents reported feeling depressed because of their condition almost every } \\
\text { day in the previous month. HRQoL for those with IBS-C is low compared to those with chronic conditions such as } \\
\text { diabetes, heart failure and heart defects, who have a high rate of mortality, and also those with asthma, migraine } \\
\text { and rheumatoid arthritis, with well-known morbidity. }\end{array}$ \\
\hline IBS-D & $\begin{array}{l}\text { With predominant diarrhea. The symptoms most frequently reported for IBS-D are: abdominal pain and } \\
\text { discomfort, abdominal bloating, distension, urgency and diarrhea. } 47 \% \text { of respondents with IBS-D stated that } \\
\text { they had little or no ability to predict their symptoms on a daily basis. When asked how IBS-D affects them, } 81 \% \\
\text { stated that they avoided situations where there was no nearby washroom. }\end{array}$ \\
\hline IBS-M & $\begin{array}{l}\text { With both constipation and diarrhea. In the United States, patients are equally distributed among IBS with } \\
\text { diarrhea (IBS-D), IBS with constipation (IBS-C), and IBS with a mixed bowel pattern (IBS-M), whereas in Europe, } \\
\text { studies have found either IBS-C ( } 45.9 \%) \text { or IBS-D ( } 50 \% \text { ) as the main pattern group. IBS-M is a heterogeneous } \\
\text { symptom group and thus requires that subclassification criteria be better defined. Use-aflaxative/antidiarrheal } \\
\text { medications adds to the diagnostic complexity in a potentially more severe subset } \\
\text { assessed for accurate subclassification. }\end{array}$ \\
\hline IBS-U & $\begin{array}{l}\text { Un-subtyped IBS, has a lower prevalence (17.8\%). Un-subtyped IBS subjects the the } \\
\text { other subtypes. }\end{array}$ \\
\hline
\end{tabular}

\section{Lifestyle Modification}

An important lifestyle adjustment that should be recommended to IBS patients is regular exercise. Mild exercise or physical activity has been shown to reduce IBS symptoms and alleviates bloating and gas production in several studies. Since regular exercise also helps to increase gastrointestinal motility it is beneficial in IBS-C patients with primary low GI movement and hard stools. As part of exercise, yoga has bec investigated due to its low impact on joints and its relativel targeted postures that can help to reduce Gl symntoms. Pranayama yoga administered twice daily has bee

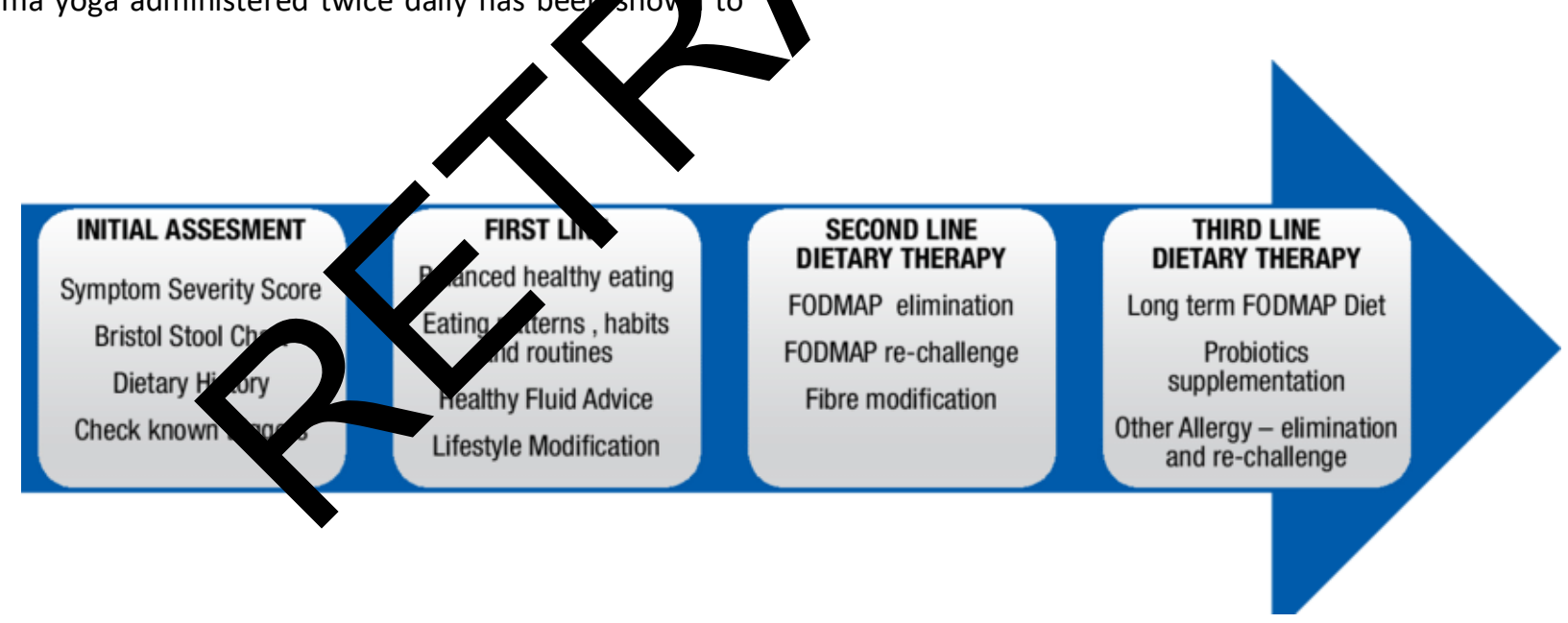

Figure 5. IBS Dietary Treatment Pathway. In the last 10 years, evidence has emerged for the restriction of a group of short chain fermentable carbohydrates which have collectively become known as FODMAPs. The common factor in these foods is the size and chain length of these carbohydrate molecules, as they all contain between 1 and 10 glucose molecules. This group of short-chain carbohydrates is susceptible to colonic fermentation by a number of possible mechanisms, which have been shown to exacerbate IBS symptoms. There is strong evidence to support three mechanisms of action: 1. Augmentation of small intestinal water 2. Increased colonic fermentation 3. Immune modulation (Source: Jankovich E, Watkins A. Case Study: The low FODMAP diet reduced symptoms in a patient with endometriosis and IBS. S Afr J Clin Nutr 2017;30(4):32-36). 


\section{Herbs and Probiotics for IBS}

Pharmacological treatment of IBS varies from antidepressants including tricyclic antidepressants and selective serotonin reuptake inhibitors, to antispasmodics, 5-HT3 antagonists, 5HT4 agonists, antibiotics, probiotics, and melatonin. But involvement of numerous factors in pathophysiology and a very significant placebo effect cause therapy of this disease to be more complex. Due to disappointing results with conventional IBS treatments, complementary and alternative medicines are becoming attractive options for many patients [126]. CAM alone and in conjunction with pharmacological treatments as an integrative approach to manage patients with IBS and improve their quality of life. Prokinetics are not specific to IBS and increase gastrointestinal motility in general by acting via dopamine and 5-HT3 receptors as antagonists or 5-HT4 receptors as agonists. Lubiprostone, a 5-HT4 agonist, has been recently approved to treat IBS-C in women through activation of chlorine channels leading to increased water secretion into the lumen which decreased transit time and associated visceral pain in patients. The common use of 5-HT3 receptor antagonists such as ondansetron and granisetron to reduce visceral pain perception in IBS-D patients has shown some benefits but is also limited by side effects [127]. Novartis has agreed to continue to supply Zelnorm ${ }^{\circledR}$ (Tegaserod maleate) for use in emergency situations, due to an increased cardiovascular risk $[128,129]$. Glaxo Wellcome (Now GSK) has informed the US FDA that it will voluntarily withdraw Lotronex ${ }^{\circledR}$ (alosetron) tablets (for IBS-D) from the market [130]. Clinical benefits of supposed spasmolytic (anti-spasmodic) agents may relate more to effects on visceral sensation than motility. A mixture of dried powdered slippery elm bark, lactulose, oat bran, and licorice root significantly improved both bowel habit and IBS symptoms in patients with constipation-predominant IBS [132]. There is a growing body of evidence which indicates therapeutic properties for ALE. Furthermore, $96 \%$ of patients rated ALE as better than or at least equal to previous therapies administered for their symptoms, and the tolerability of ALE was very good [133]. In IBS, the gastrointestinal flora may undergo both qualitative and quantitative and the most common finding is a decrease in $t$ populo on 'good bacteria' such as Bifidobacteria and Lacilli an the faecal microflora has increased numbers facuh ive or anisms. Probiotics may be useful in the $m$ agem of however dose and specific bacterial strain portant In vivo studies have identified some of $t$ variab, that etermine the survival of probiotics throug (th GI tract, a some have attempted to quantify the degree of sun al of the dose administered. This was found to y 10 to $\%$ depending on the probiotic species used and the dere administered [131].

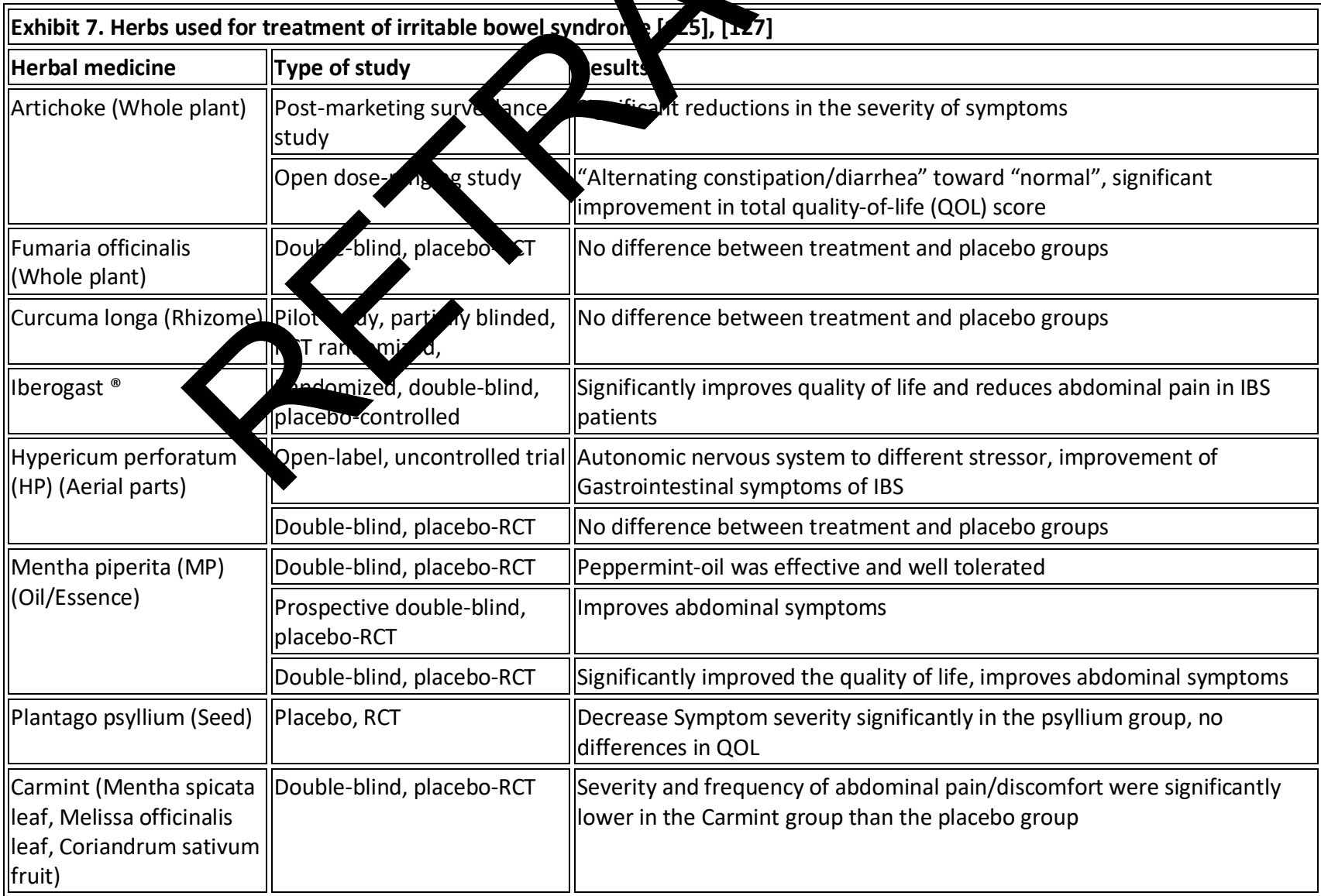




\section{Inflammatory Bowel Disease (IBD)}

IBS, a common gastrointestinal disorder involving the gut-brain axis; IBD, a chronic relapsing inflammatory disorder. Both have significant overlap in terms of symptoms, pathophysiology, and treatment, suggesting the possibility of IBS and IBD being a single disease entity albeit at opposite ends of the spectrum [133]. A significant association between IBD and later occurrence of PD, which is consistent with recent basic scientific findings of a potential role of Gl inflammation in development of parkinsonian disorders [134]. An area of recent research interest where the role of adiposity is avidly discussed is in IBD, which presents mainly as Crohn's disease (CD) and ulcerative colitis (UC) [135]. IBD is a chronic illness, and sexual dysfunction is a well-recognized complication of chronic illness [136]. A subgroup of IBD patients considered diet to be a more important and successful managing tool than medication to relieve their disease symptoms [137].

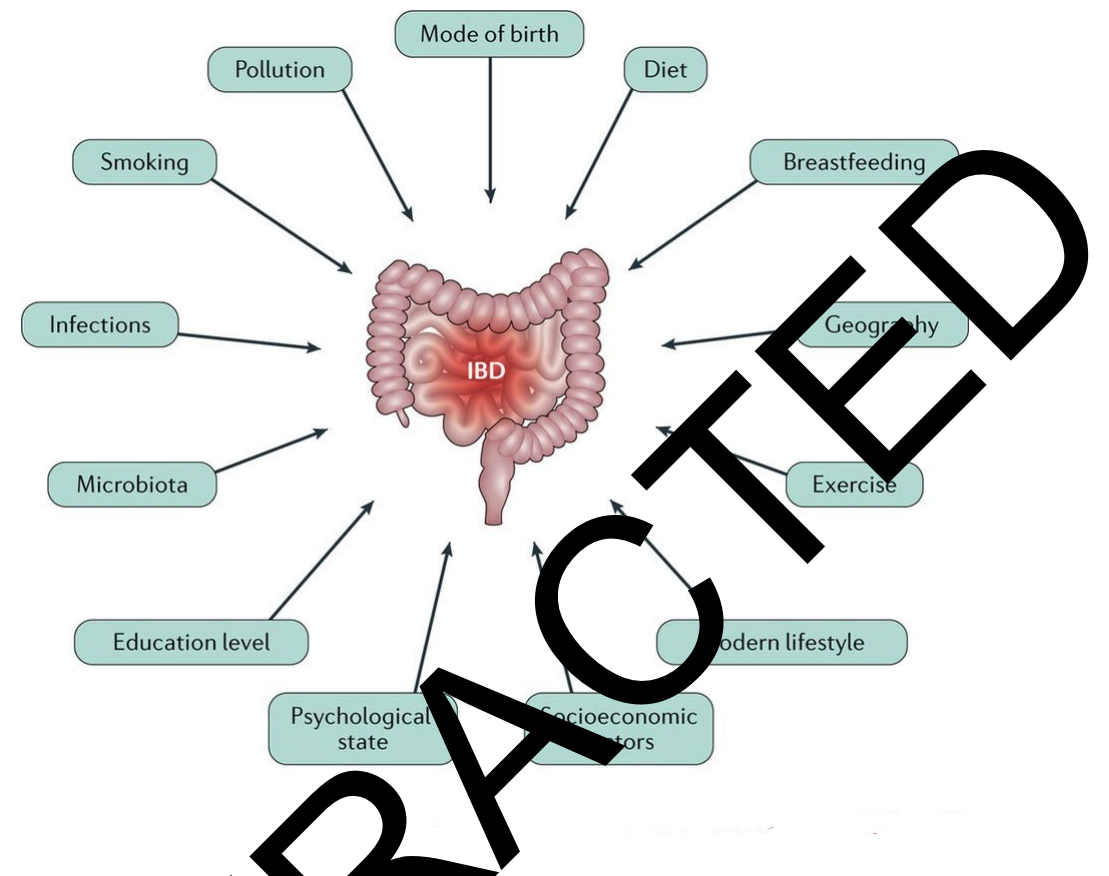

Figure 6. Environmental triggers in IBD. environmental triggers have been associated Smoking remains the most widely studied and replico. d risk factor, contributing to increased risk and se ity of CD whil confering protection against UC. Lower plasm itamin is associated with an increased risk of Crohn's disease, and on 1 D sup entation may prevent relapse of disease ral dicat including oral contraceptives, post-men ausal ormon eplacement, aspirin, NSAIDs, and antibiotics $y$ in mechanisms of effect rem ng inadequately defined. There is continuing evidence that depres n and psychosocial stress may play a role in the pathogenesis of both $\backsim$ and UC, while at the same time also increasing risk for disease flares. There is also a growing understanding of the role of diet on IBD, in particular through its effect on the microbiome. Animal protein intake and $n-6$ fatty acids may increase risk of UC while n-3 fatty acids and dietary fiber may confer protection. The effect of diet on established disease remains poorly studied. There is need for routine measurement of a spectrum of environmental exposures in prospective studies to further our understanding (Source: Ananthakrishnan AN. Environmental triggers for inflammatory bowel disease. Curr Gastroenterol Rep. 2013;15(1):302).

\section{Prevalence and Economic Burden of IBD}

$I B D$, including $U C$ and $C D$, are chronic, disabling, and progressive disorders characterized by lifelong treatment and whose incidences are increasing in Asia [141]. EIMs of IBD occur in up to $55 \%$ of patients with $C D$ and $35 \%$ of those with UC. Although arthritis/arthralgia is the most common EIM in both disorders, multiple organs may be affected including skin, eye and liver [145]. Approximately 2.5 million-3 million people in Europe are affected by IBD. The highest rates of IBD are reported in Scandinavia and the UK. The incidence and prevalence of UC in the UK is estimated to be 14 cases per 100,000 person-years and 244 cases per 100,000 people, respectively. The incidence and prevalence of $C D$ in the UK is estimated to be 7-11 per 100,000 and 85-145 cases per 100,000 people, respectively [144]. An increasing number of these children are being treated with immunosuppressive and biological medications. Although these medications can improve the short-term outcome and quality of life of children with IBD, they have been associated with opportunistic infections, malignancy, and lymphoproliferative disorders among IBD populations. It is estimated that $15 \%$ to $20 \%$ of all cases of IBD are diagnosed in the childhood and adolescent period [146]. Patients with IBD have a 2- to 3-fold increased risk of colorectal cancer death; therefore, colorectal cancer surveillance via colonoscopy is recommended for IBD patients 
[147]. Environmental factors probably have a major role in IBD; antibiotic use, childbirth mode, breastfeeding, air pollution, NSAID use, hypoxia or high altitude, diet and urban environments have been studied [148].

\section{Rationale of DS and Probiotics in IBD}

A recent survey by de Vries et.al., 2019, DS were used by $68 \%$ of the IBD patients. Although over $71 \%$ had received dietary advice mainly by dieticians, $81 \%$ stated that the main source of their nutritional knowledge related to IBD was their own experience [137]. Despite recent advancements, Crohn's disease and ulcerative colitis remain chronic and progressive diseases. One of the primary reasons for persistent inflammation and bowel damage is failure of medical therapy. With growing therapeutic options, there is an increased temptation to quickly move to the next therapy and label the prior therapy as a failure; however, this can lead to inadequate optimization of medications and poor control of disease. On the other hand, failure to recognize ongoing mucosal inflammation despite optimized treatment and moving to the next agent can lead to progression of disease and long-term complications [138]. Anti-tumor necrosis factor antibodies have led to a revolution in the treatment of IBD; however, a sizable proportion of patients does not respond to therapy. There is increasing evidence suggesting that treatment failure may be classified as mechanistic (pharmacodynamic) pharmacokinetic, or immune-mediated. Data regarding the contribution of these factors in children with IBD treated with infliximab (IFX) are still incomplete [139]. Endoscopi aty py has been explored and used in the management strict es, fistulas/abscesses, colitis-associated neoplasin acute or chronic leaks, and obstructions 40]. Fo several decades, medical treatments for IBD biological therapies (i.e., aminosalicylates, thiopurines, and steroids), which provide symptomatic improvement but do not change the disease course [141]. Anti-TNF agents (infliximab, adalimumab, and certolizumab) have reduced the need for surgery and hospitalization and have improved the quality of life of patients by changing the course of the disease. Thus, guidelines recommend the use of anti-TNF agents initially in moderate-to-severe IBD or if non-biological therapy fails. However, these treatments have not been effective in all patients, and patients who initially responded to treatment have also lost their responsiveness over time. Furthermore, although anti-TNF agents are generally well tolerated, their use is associated with adverse effects, including risks of infection and malignancies $[142,143$

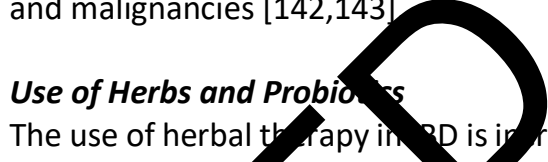
be assumed th the ficach herbal therapies in IBD is promising. The st mportant clinical trials conducted so far refer to th use of stic $m$, tormentil extracts, wormwood herb, $\mathrm{N} n$ aestiv germinated barley foodstuff, and boswellia sen ta. In ulcerative colitis, Triticum aestivum, arographis $p d$ iculata extract and topical Xilei-san were superior taplacebo in inducing remission or clinical response, nd curcl hin was superior to placebo in maintaining ission boswellia serrata gum resin and plantago ovata seeds were as effective as mesalazine, whereas oenothera bromis had similar relapse rates as $\omega-3$ fatty acids in the treatment of ulcerative colitis. In Crohn's disease, mastic gum, Artemisia absinthium, and Tripterygium wilfordii were superior to placebo in inducing remission and preventing clinical postoperative recurrence, respectively [149].

\begin{tabular}{|c|c|c|c|}
\hline Herbal medicine & & Ref No. & Results \\
\hline $\begin{array}{l}\text { Triticum aestivum } \\
\text { (Poaceae) }\end{array}$ & & 150 & $\begin{array}{l}\text { Treatment was associated with significant reduction in the overall } \\
\text { disease activity index and in the severity of rectal bleeding. Apart } \\
\text { from nausea, no other serious side effects were noticed }\end{array}$ \\
\hline $\begin{array}{l}\text { Andrographis } \\
\text { paniculata }\end{array}$ & & 151 & $\begin{array}{l}\text { Compared with Mesalazine }(4.5 \mathrm{mg} / \text { day }) \text {, there were no significant } \\
\text { differences between the two treated groups when considering the } \\
\text { clinical efficacy rates or the safety profile }\end{array}$ \\
\hline $\begin{array}{l}\text { Boswellia serrata } \\
\text { (Burseraceae) }\end{array}$ & Single Centered study & 152 & $\begin{array}{l}\text { Compared with Sulfasalazine, all parameters tested improved after } \\
\text { treatment with Boswellia serrata gum in } 82 \% \text { patients }\end{array}$ \\
\hline Artemisia absinthium & $\begin{array}{l}\text { Randomized, double- } \\
\text { blind multicentre study }\end{array}$ & 153 & $\begin{array}{l}\text { Compared with placebo, after } 8 \text { weeks of treatment with wormwood, } \\
\text { there was almost complete remission of symptoms in } 65 \% \text { of the } \\
\text { patients, }\end{array}$ \\
\hline $\begin{array}{l}\text { Tripterygium } \\
\text { wilfordii Hook F } \\
\text { (TWHF) }\end{array}$ & $\begin{array}{l}\text { Randomized controlled } \\
\text { trials }\end{array}$ & 154 & $\begin{array}{l}\text { Patients receiving mesalazine experienced less adverse events, but no } \\
\text { significant difference was found about ADEs resulted withdrawal in } \\
\text { the } 3 \text { groups. In addition, compared with low-dose TwHF and } \\
\text { mesalazine, the authors also detected significant superiority of high- } \\
\text { dose TwHF arm in the decrease of CDAI and SESCD }\end{array}$ \\
\hline $\begin{array}{l}\text { Evening primrose oil } \\
\text { Oenothera biennis }\end{array}$ & $\begin{array}{l}\text { Randomized controlled } \\
\text { trials }\end{array}$ & 155 & $\begin{array}{l}\text { Oenothera biennis had similar relapse rates as omega-3 fatty acids in } \\
\text { the treatment of UC }\end{array}$ \\
\hline
\end{tabular}


Altered gut bacteria and bacterial metabolic pathways are two important factors in initiation and progression of IBD. However, efficacy of probiotics in remission of patients with IBD has not been characterized [156]. Among the effects claimed for probiotics are beneficial immunomodulation, reduction of serum cholesterol, improved lactose digestion and protection against colon cancer $[157,158]$. Probiotic administration improved the clinical symptoms, histological alterations, and mucus production in most of the evaluated animal studies, but some results suggest that caution should be taken when administering these agents in the relapse stages of IBD [158]. In CD, the entire gastrointestinal tract can be involved and the inflammation can extend through the intestinal wall from mucosa to serosa. Areas of inflammation may be interspersed with relatively normal mucosa. In $C D$, the predominant symptoms are diarrhea, abdominal pain and weight loss whereas in UC diarrhea is the main symptom, often accompanied by rectal bleeding. Both diseases are common in the industrialized world, with highest incidences in North America and Northern Europe [159].

\begin{tabular}{|c|c|c|c|}
\hline \multicolumn{4}{|c|}{ Exhibit 8. Summary of probiotic anti-inflammatory effects in In Vitro studies. [160] } \\
\hline Cell Type & Probiotic Strain & Type of Study & \\
\hline human DC & L. casei Shirota & In vitro & $\begin{array}{l}\text { DC from UC patients samples } \\
\text { and loss of IL-22 and IFN secre an incre of IL-4 production } \\
\text { restored the normal stin atory capas }\end{array}$ \\
\hline IPEC-J2 model| & $\begin{array}{l}\text { L. plantarum strain } \\
\text { CGMCC1258 }\end{array}$ & In vitro & $\begin{array}{l}\text { f IL- } 8 \text {, TNF- } \alpha \text {, and } \\
\text { arum treatment } \\
\text { of occludin }\end{array}$ \\
\hline PIE cells & $\begin{array}{l}\text { L. delbrueckii subsp. } \\
\text { delbrueckii TUA4408L }\end{array}$ & In vitro & $\begin{array}{l}\text { I MAP, nd NF-KB pathways induced by } E \text {. coli 987P } \\
\text { regulated through upregulation of TLR negative } \\
\text { regulators, principally by TLR2 }\end{array}$ \\
\hline IEC-6 & $\begin{array}{l}\text { E. coli Nissle } 1917 \text { and } L . \\
\text { rhamnosus GG }\end{array}$ & In vitro & $\begin{array}{l}\text { probiotics could prevent or inhibit } \\
\text { of intestinal barrier function induced } \\
\text { by } 5 \text {-FU }\end{array}$ \\
\hline DC & $\begin{array}{l}\text { L. paracasei CNCM I-4034, } \\
\text { B. breve CNCM I-4035, and } \\
\text { L. rhamnosus CNCM I-4036 } \\
\end{array}$ & & $\begin{array}{l}\text { nd TGF- } \beta 2 \text { secretion. CFS treatment } \\
\text { atory cytokines and chemokines }\end{array}$ \\
\hline
\end{tabular}

Peptic Ulcer Disease (PUD)

The presenting symptoms of PUD vary dependh on the age of the patient. Hematemesis or melen s reported in $s$ to half of patients with PUD. Infants and yo Iger ct dren usually present with feeding difficulty, vomiting, co cpisode hematemesis, or melena [161]. The majo pton un omplicated PUD is upper abdominal dyspe sa suc as bloc.ng, early satiety, and nausea. $H$. pylori in the crucial role in the pathogenesis of PUD. H. p) ri infection is involved in various gastroduodenal pathologies, $y d$ evokes the production of proinflammatory interleukin-1beta, leading to the reduction of blood flow to the gastroduodenal tract and increasing the risk of peptic ulcers. H. pylori can colonize not only in the stomach, but also in the oral cavity. The oral cavity may be a reservoir for $H$. pylori and a potential source for infection of the stomach [162]. EGD is most accurate diagnostic test with sensitivity and specificity up to $90 \%$ in diagnosing gastric and duodenal ulcers. Surgical treatment is indicated if the patient is unresponsive to medical treatment, noncompliant or at high risk of complications. Surgical options include vagotomy or partial gastrectomy [163]. Factors that increase risk of developing peptic ulcer include smoking, older individuals, O blood type, and stress. Peptic ulcers that tend to heal longer than duodenal ulcer is at higher risk of developing gastritis and gastric malignancy [168]. Classically, patients with duodenal ulcers complain of worsening abdominal pain on an empty stomach and describe hunger or abdominal pain two to three hours after meals or at night. In contrast, patients with gastric ulcers report nausea, vomiting, weight loss and post-prandial abdominal pain. Elderly patients are often minimally symptomatic and some patients with untreated PUD may have intermittent symptoms due to spontaneous healing and then relapse due to persistence of risk factors, such as continued NSAIDs use or $\mathrm{H}$. pylori infection [169].

\section{Prevalence and Economic Burden of PUD}

The prevalence of PUD ranges from 0.12 to $1.5 \%$ and increases with age [162]. H. pylorus is a gram-negative bacillus that is found within the gastric epithelial cells. This bacterium is responsible for $90 \%$ of duodenal ulcers and $70 \%$ to $90 \%$ of gastric ulcers, up to $85 \%$ of individuals infected with $\mathrm{H}$. pylori are asymptomatic and have no complications [163], [165]. PUD is a global problem with a lifetime risk of development ranging from $5 \%$ to $10 \%$ [164]. In many studies worldwide (United States, Brazil and China), the prevalence of $\mathrm{H}$. pylori among subjects with dyspepsia was $28.9 \%, 57 \%$, and $84 \%$ respectively [165]. The prevalence differs in the world population between the duodenal and gastric ulcers, and the mean age of people 
with the disease is between 30 and 60 years, but it can happen in any age [166]. Environmental elements such as alcohol and nicotine can inhibit or reduce secretion of mucus and bicarbonate, increasing acid secretion. Genetic factors can influence, and children of parents with duodenal ulcer are three times more likely to have ulcer than the population [167]. 30\% PUD patients are smoker [168]. NSAIDs account for over $90 \%$ of all ulcers and approximately $25 \%$ of NSAID users will develop peptic ulcer disease [169]. Approximately 500,000 persons develop PU in the United States each year [170]. Peptic ulcers accounted for 301,000 deaths in 2013, which is down from 327,000 deaths in 1990 [174]. Low socioeconomic status and concrete life difficulties are associated with peptic ulcer in the general population cross-sectionally and prospectively after adjustment for major physical risk factors, lending credence to a relationship between psychological stress and peptic ulcer [175].

\section{Lifestyle Modification for PUD}

The physicochemical properties of fiber fractions produce different physiological effects in the organism. Soluble fibers, found in apple, oatmeal, and pear are responsible, for instance, for an increased viscosity in the intestinal content. Insoluble fibers (whole grains, granola, flaxseed) increase stool bulk, reduce transit time in the large intestine, and make fecal elimination easier and quicker [171]. Physical activity has numerous health benefits and may also represent a costeffective approach to the prevention of peptic ulcers. At the levels observed in this study among the moderately active group (walking or jogging $<10$ miles a week), possible adverse effects-for example, injuries-are minimized. In the general population, only about a third of adults undertake this much physical activity.

Strategies to promote safe walking, jogging, and cycling may benefit many aspects of health in addition to the cardiovascular and musculoskeletal system 2]. Moderate physical activity could have a favorable in sact on number of risk factors for peptic ulceration. It $\&$ Id reduc gastric secretions and enhance immune $\mathrm{cction}$, th th atter reducing the risk of Helicobacter py ri inf tion. oderate activity might also reduce anxinty nd chcournge the adoption of a healthy lifestyle, ath an tance of smoking and an excessive consur th of alc . However, prolonged endurance exercise seen likely to have a negative impact, suppressing imure function reducing mucosal blood flow, and calling for frequent administration of NSAIDs [176].

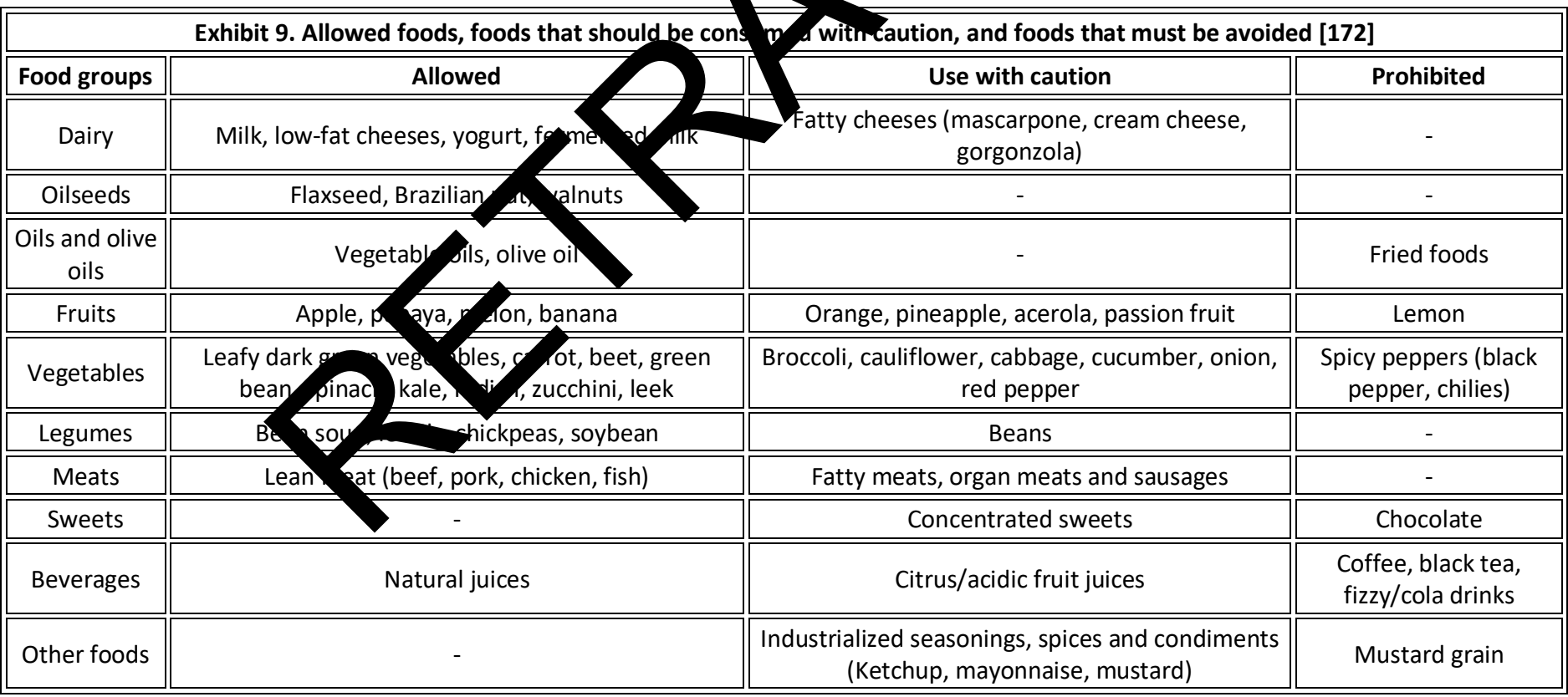

\section{Herbs and Probiotics for PUD Management}

The potential of plants as source of new drugs still offers a large field for scientific research. Even if is observed a large number of known plants, a small percentage has already been phytochemically investigated and only a fraction of them has already been assessed to determine its pharmacological potential. 


\begin{tabular}{|c|c|}
\hline \multicolumn{2}{|r|}{ Exhibit 10. Herbs for PUD Management } \\
\hline Plant name/family & Description \\
\hline $\begin{array}{l}\text { Psidium guajava L., popularly } \\
\text { known as guava (Myrtaceae) }\end{array}$ & $\begin{array}{l}\text { The leaves have shown the ability to protect the stomach against ulceration by inhibiting gastric lesions, } \\
\text { reducing gastric secretory volume, and acid secretion, and raising the gastric } \mathrm{pH} \text {. This anti-ulcer activity, } \\
\text { resulting from the protection of the mucosa, was related to the flavonoids in the leaves [179] }\end{array}$ \\
\hline $\begin{array}{l}\text { Aegle marmelos (Rutaceae), } \\
\text { Bael Fruit }\end{array}$ & $\begin{array}{l}\text { Ulcers are induced by aspirin plus pylorus ligated gastric ulceration in rats and aqueous extract of leaves is to } \\
\text { be administered orally for } 21 \text { days, daily dose of } 1 \mathrm{gm} / \mathrm{kg} \text {. The result indicated a significant reduction in the } \\
\text { ulcer lesion count compared to control [180] }\end{array}$ \\
\hline $\begin{array}{l}\text { Allium sativum } \\
\text { (Liliaceae) garlic }\end{array}$ & 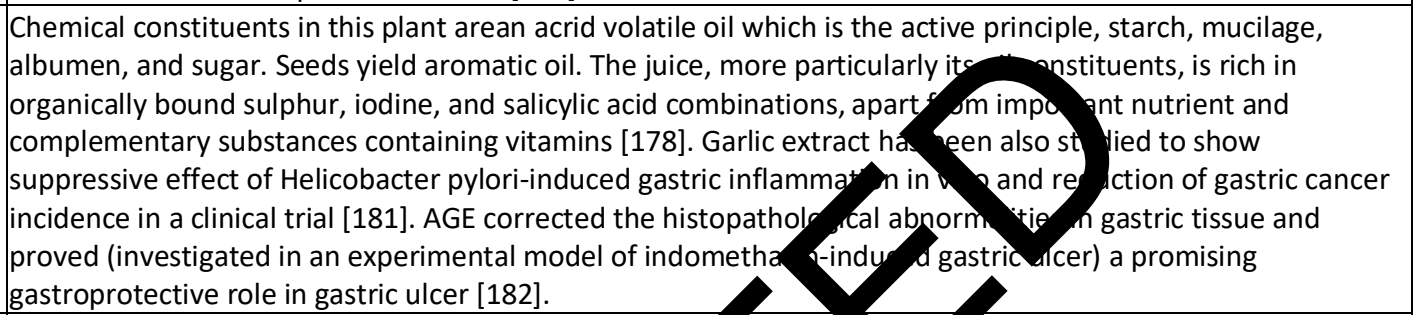 \\
\hline $\begin{array}{l}\text { Azadirachta indica } \\
\text { (Meliaceae) Neem }\end{array}$ & $\begin{array}{l}\text { Administration of lyophilized powder of the extract fo days at do } 30 \mathrm{mg} \text { twice daily showed } \\
\text { significant decrease (77\%) of gastric acid secretion } \\
\text { weeks almost completely healed the duodenal ulcers and on ase of esophageal ulcer and one case of gastric } \\
\text { ulcer healed completely when administrated cthe-dose of } 30 \\
\text { twice daily for } 6 \text { weeks [184] }\end{array}$ \\
\hline $\begin{array}{l}\text { Bauhinia purpurea L. } \\
\text { (Fabaceae) }\end{array}$ & 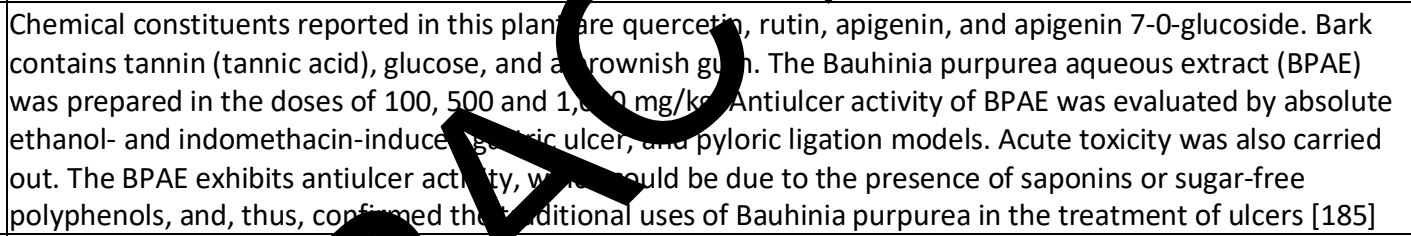 \\
\hline 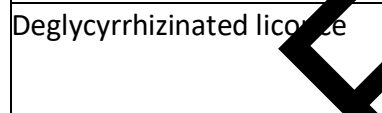 & $\begin{array}{l}\text { ct has been used for peptic ulce } \\
\text { psin secretions by covering the }\end{array}$ \\
\hline Honey & $\begin{array}{l}\text { atural honey is composed of around } 82 \% \text { carbohydrates, water, phytochemicals, proteins, minerals, and } \\
\text { artioxidants. It is also beneficial in } \mathrm{H} \text {. pylori-associated ulcer because honey is a powerful antibacterial agent. } \\
\text { In gastric curative effects of manuka honey in rat model with acetic acid-induced chronic gastric ulcer, manuka } \\
\text { honey provided significant gastroprotective effects in acute gastric ulcer animal model [189] }\end{array}$ \\
\hline
\end{tabular}

It has been shown that lactobacilli are particularly useful in promoting gastric ulcer healing in rats, when administered as an individual probiotic strain, such as Lactobacillus rhamnosus GG, Lactobacillus gasseri OLL2716, or Lactobacillus acidophilus or as a probiotic mixture, VSL\#3. Lactobacillus rhamnosus GG increases the cellular proliferation to apoptosis ratio and therefore promotes regeneration of epithelial cells, particularly at the ulcer margins. In clinical studies, a probiotic mixture was demonstrated to be better than a single strain for improving the characteristics of indigenous microflora [191]. 


\begin{tabular}{|c|c|c|c|}
\hline \multicolumn{4}{|c|}{ Exhibit 11. Summary of studies on the therapeutic effects of probiotics in Gastric Ulcer [191] } \\
\hline Probiotic strain(s) & $\begin{array}{l}\text { Modeling } \\
\text { method }\end{array}$ & Lesions & Effects of probiotics \\
\hline Lactobacillus spp. & Acetic acid & Gastric ulcer & Enhance healing of a pre-existing gastric ulcer \\
\hline Lactobacillus rhamnosus GG & Acetic acid & Gastric ulcer & $\begin{array}{l}\text { Inhibit cell apoptosis to proliferation ratio, and induce } \\
\text { angiogenesis }\end{array}$ \\
\hline Lactobacillus gasseri OLL 2716 & Acetic acid & Gastric ulcer & $\begin{array}{l}\text { Accelerate healing by enhancing generation of gastric mucosal } \\
\text { prostaglandin E2 }\end{array}$ \\
\hline $\begin{array}{l}\text { Lactobacillus acilidophilus encapsulated in } \\
\text { ginger extract }\end{array}$ & Stress & Gastric ulcer & $\begin{array}{l}\text { Improve healing by restoring all biochemical, physiological and } \\
\text { histological changes }\end{array}$ \\
\hline $\begin{array}{l}\text { Lactobacillus acidophilus and alginate } \\
\text { floating beads }\end{array}$ & Stress & Gastric ulcer & $\begin{array}{l}\text { Improve healing by restoring all biochemical, physiological and } \\
\text { histological changes }\end{array}$ \\
\hline $\begin{array}{l}\text { Probiotic mixture (VSL\#3) (8 probiotic } \\
\text { strains) }\end{array}$ & Acetic acid & Gastric ulcer & genesis via upregulation of \\
\hline Saccharomyces boulardii & Ibuprofen & Gastric ulcer & Potential treatr \\
\hline $\begin{array}{l}\text { Polysaccharides fractions (PSFs) of } \\
\text { Bifidobacterium breve and bifidum }\end{array}$ & $\begin{array}{l}\text { Acetic acid and } \\
\text { ethanol }\end{array}$ & $\begin{array}{l}\text { Gastric erosion } \\
\text { and ulcer }\end{array}$ & $\begin{array}{l}\text { easing expression of } \\
\text { and 6-ketoprostaglandir }\end{array}$ \\
\hline $\begin{array}{l}\text { Probiotic mixture ( } 2 \text { bacterial strains) and } \\
\text { composite probiotic ( } 3 \text { bacterial strains) }\end{array}$ & Stress & $\begin{array}{l}\text { Gastric erosion } \\
\text { and ulcer }\end{array}$ & g through the restoration \\
\hline Probiotic mixture (14 bacterial strains) & Stress & $\begin{array}{l}\text { Gastric } \\
\text { mucosal } \\
\text { lesions }\end{array}$ & $\begin{array}{l}\text { downregulate pro- } \\
\text { e anti-inflammatory }\end{array}$ \\
\hline
\end{tabular}

Promising results for studies exploring both prophylactic and Renutic elrects (Exhibit 11) of probiotics have been obtained. The studies concerning the roles of probiotics in gastric ulcer healin rer in the literature were mainly conducted in rats. These studies were based on the use of either individual pro stra , such as Lactobacillus rhamnosus GG, Lactobacillus gasseri OLL2716, Lactobacillus acidophilus, Escherichia col vissle 317, B jobacterium animalis VKL/VKB, Bifidobacterium bifidum/brevis

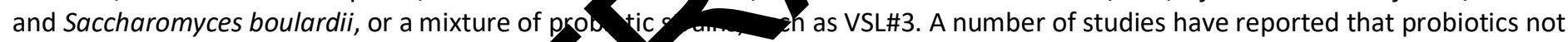
only inhibit the development of acute gastrig Mucosan ssions, but also accelerate the process of healing of induced gastric ulcers [191].

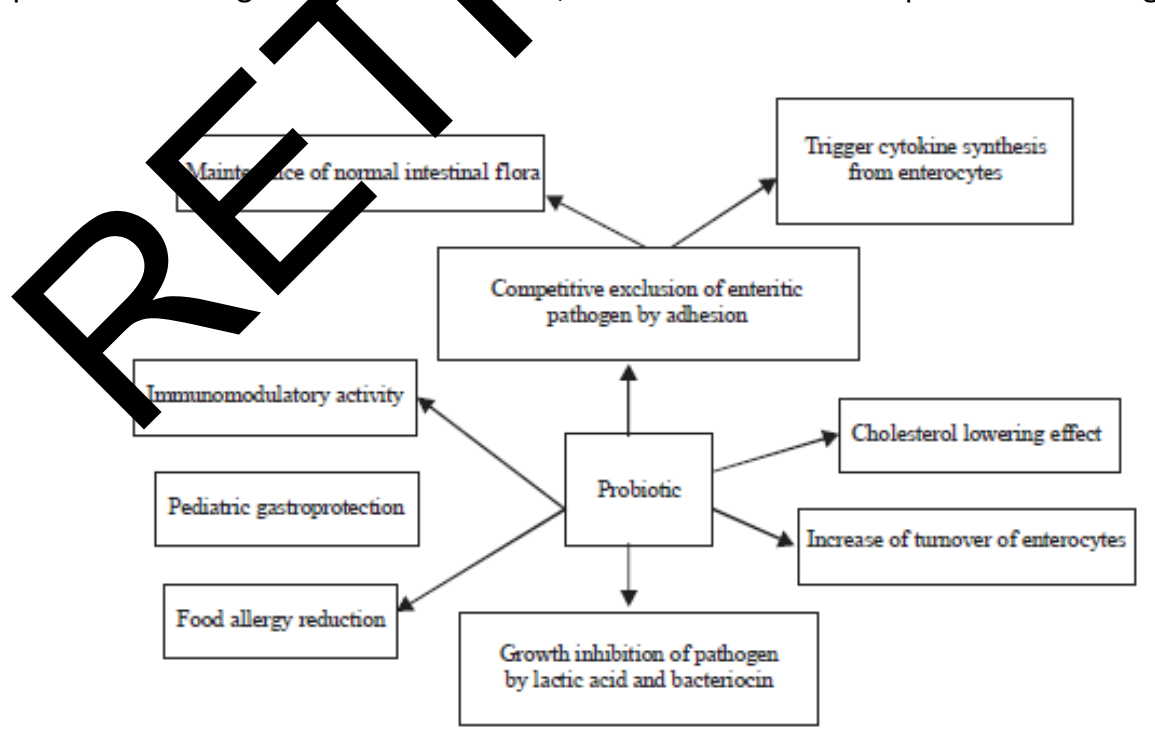

Figure 7. Mechanisms of action of probiotics. Probiotics are engaged to adherence to host epithelial tissue, acid resistance and bile tolerance, elimination of pathogens or reduction in pathogenic adherence production of acids, hydrogen peroxide and bacteriocins antagonistic to pathogen growth, safety, non-pathogenic and non-carcinogenic, and Improvement of intestinal microflora. Prebiotics of proven efficacy are able to modulate the gut microbiota by stimulating indigenous beneficial flora while inhibiting the growth of pathogenic bacteria therein. Preferred target organisms for prebiotics are specific. belonging to the Lactobacillus and Bifidobacterium genera. The most efficient prebiotics may also reduce or suppress numbers and activities of organisms seen as pathogenic (Bandyopadhyay B, Mandal NC. Probiotics, Prebiotics and Symbiotic - In Health Improvement by Modulating Gut Microbiota: The Concept Revisited. Int. J. Curr. Microbiol. App. Sci (2014) 3(3): 410-420) 
Probiotics can also protect the integrity of the gastric mucosal barrier by upregulating prostaglandin, mucous secretion, tight junction protein expression and cell proliferation, and by inhibiting apoptosis $(43,48,130-132)$. In rats, the administration of Bifidobacterium bifidum BF-1 or Bifidobacterium animalis VKL and VKB has been found to protect the gastric mucosa through either preventing the mucous barrier from degradation or increasing gastric mucous production. The probiotic mixture VSL\#3 protects the epithelial barrier and upregulates the expression of tight junction proteins (occludin and zonula occludens-1) in vivo and in vitro via the activation of p38 or mitogen-activated protein (MAP) kinase and extracellular signal-regulated kinase (ERK) signaling pathways. Mennigen et al demonstrated that probiotics can strengthen the gastric mucosal barrier by inhibiting the redistribution and expression of tight junction proteins and blocking apoptosis (135). The probiotic strains Lactobacillus gasseri OLL2716, Lactobacillus rhamnosus GG and Escherichia coli Nissle 1917 are able to protect the altered gastric mucosal barrier $(43,48,114)$. In humans, Gotteland et al found that pretreatment with Lactobacillus GG protected against indomethacin-induced disruption of the gastric mucosal barrier [191].

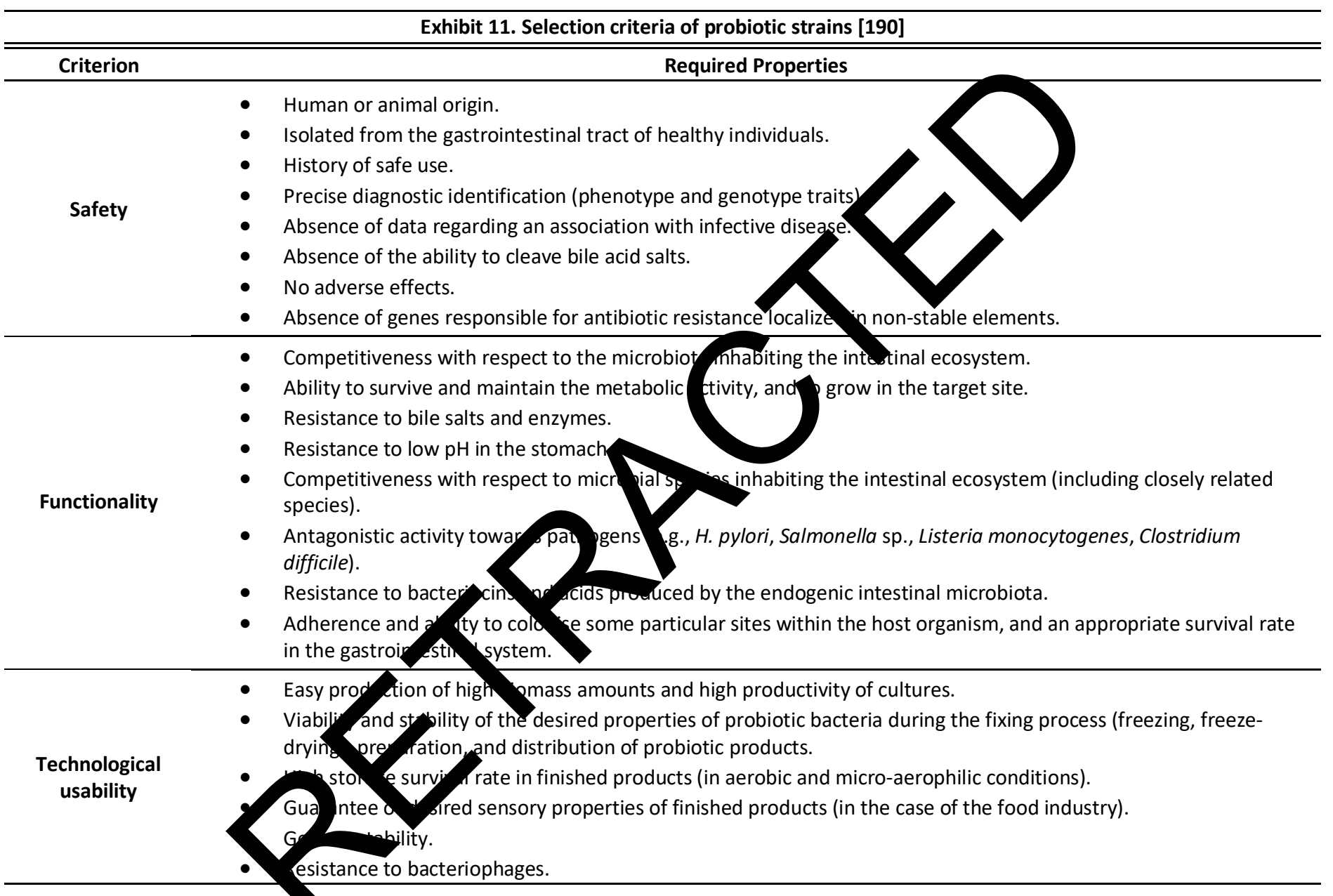

The mode of action of probiotics is not completely understood but they may act as surrogate normal microflora following antibiotic therapy until recovery is achieved. However, probiotic combinations appeared to induce only minor changes in the microbiota. For instance, the mechanisms of action of S. boulardii include luminal action (anti-toxic effect, antimicrobial activity), trophic action (enzymatic activity, increased $\lg A$ ) and mucosal-anti-inflammatory signaling effects (decreased synthesis of inflammatory cytokines). Short-chain fatty acids (SCFAs) and bacteriocin proteins have been implicated in the inhibition of $\mathrm{H}$. pylori by lactic acid bacteria. SCFAs such as formic, acetic, propionic, butyric and lactic acids are produced as a result of the metabolism of carbohydrates by probiotics and play an important role in decreasing the $\mathrm{pH}$ in vitro. Their antimicrobial activity could be due to the inhibition of urease activity by high lactic acid producers, such as Lactobacillus salivarius and Lactobacillus casei Shirota. Lactobacillus salivarius significantly decreased IL-8 production [IL-8 is induced after injection of virulence factor CagA into epithelial cells] upon exposure to $\mathrm{H}$. pylori and led to CagA accumulation in $\mathrm{H}$. pylori cells, presumably as a result of loss of functionality of the Cag secretion system. Alterations in gastrointestinal permeability are an initial step in the development of lesions such as ulcers. Probiotics may stabilize the intestinal barrier by stimulating the expression of gastric mucins, decreasing bacterial overgrowth and stimulating local immune responses and the release of antioxidant substances [192]. 


\section{Conclusion}

This review is conducted and correlate the published literature on the effectiveness of herbs and probiotics, for the treatment of FAPDs. Despite its common use, research on the efficacy, safety, and optimal dosage remains limited. Many responsible members of the dietary supplements industry have taken significant steps to regain consumer trust by improving transparency along the supply chain, enhancing traceability of raw botanical materials, and bringing attention to ingredients with potential adulteration concerns, among other efforts. Lifestyle and food habit also found important factor to improve GI related disorders to much extent. Several randomized controlled trials have now shown that microbial modification by probiotics may improve gastrointestinal symptoms and multiorgan inflammation in rheumatoid arthritis, ulcerative colitis, and multiple sclerosis. In the USA, microorganisms used for consumption purposes should have the GRAS status, regulated by the FDA. In Europe, EFSA introduced the term of QPS. The QPS concept involves some additional criteria of the safety assessment of bacterial supplements, including the history of safe usage and absence of the risk of acquired resistance to antibiotics. Future work will need to carefully assess safety issues, selection of optimal strains and combinations, and attempts to prolong the duration of colonization of beneficial microbes. This doesn't mean conventional therapies don't work, it just means that experts haven't studied them enough to know if they do. The mo important thing is safe healing and better life. To ensure this researchers needs to work more on both conventi complimentary drugs.

Abbreviations: The American College of Gastr Atero, (ACG); Gastroesophageal Reflux Disease (GERD); Pr Pump 1. ibitors (PPIs); Recurrent Abdominal Pain (RAP); Fu,ction gastrointostinal disorders (FGIDs); Postprandial Di iess Syno me (PDS); Complementary and Alternative edicine (CAM); Functional Dyspepsia (FD); Chronic Constipat (CC Quality Of Life (QoL); European Society for Paediatric Gas Mterolo Hepatology and Nutrition (ESPGHAN); Nor perico sor Pediatric Gastroenterology, Hepato' sy and utrition.ASPGHAN); Congenital Sucrase-Isomaltase Defio cy FODMAPs (Fermentable Oligosaccharides, Disacchario Monosaccharides and Polyols); SIBO (Small Intestinal Bacterial Ove rowth); NCGS (Nonceliac Gluten Sensitivity); ATIs ( $\alpha$-Amylase/Trypsin Inhibitors); Ni ACM (Nickel Allergic Contact Mucositis); Health-Related quality of life (HRQoL); Healthcare Resource Utilization (HRU); 5-Hydroxytryptamine-3 Receptor (5-HT3); Food and Agriculture Organization of the United Nations (FAO); Department of Health (DOH); Artichoke Leaf Extract (ALE); Inflammatory Bowel Disease (IBD); Parkinson's Disease (PD); Crohn's Disease (CD); Ulcerative Colitis (UC); Dietary Supplement (DS); Extraintestinal Manifestations (EIMs); Crohn's Disease Activity Index (CDAI); Simple Endoscopic Score for Crohn's Disease (SES-CD); Peptic Ulcer Disease (PUD); Esophagogastroduodenoscopy (EGD); Bauhinia Purpurea Aqueous Extract (BPAE); Herbal Dietary Supplements (HDS); Generally Regarded As Safe (GRAS); Qualified Presumption of Safety (QPS); European Food Safety Authority (EFSA); Mitogen-Activated Protein (MAP); Extracellular Signal-Regulated Kinase (ERK); ShortChain Fatty Acids (SCFAs); Cytotoxin-associated gene A (CagA)

\section{References}

1. Sandhu DS, Fass R. Current Trends in the Management of Gastroesophageal Reflux Disease. Gut Liver. 2017;12(1):7-16.

2. Nasrollah L, Maradey-Romero C, Jha LK, Gadam R, Quan SF, Fass R. Naps are associated more commonly with gastroesophageal reflux, compared with nocturnal sleep. Clin Gastroenterol Hepatol. 2015;13:94-99. doi: 10.1016/j.cgh.2014.05.017.

3. Fass R. Non-erosive reflux disease (NERD) and erosive esophagitis: a spectrum of disease or special entities? Z Gastroenterol. 2007;45:1156-1163. doi: 10.1055/s-2007963628.

4. Poh $\mathrm{CH}$, Navarro-Rodriguez T, Fass R. Review: treatment of gastroesophageal reflux disease in the elderly. Am J Med. 2010;123:496-501. doi: 10.1016/j.amjmed.2009.07.036.

5. Jacobson BC, Somers SC Kelly CP, Camargo CA., Jr Body-mass index and nptoms o astroesophageal reflux in women. N Engl J Med. $06 ; 354: 23$-2348. doi: 10.1056/NEJMg S4391.

6. Kaltenbach T ackety, GeN Are lifestyle measures effective in tient vith gastroesophageal reflux disease? An eviden based proach irch Intern Med. 2006;166:965-971. doi. 001/arch o.9.965.

7. Yamasak O'Neil J, ass R. Update on Functional Heartburn. Gastroente Hepatol (N Y). 2017;13(12):725-734. Fass R. Erosivesophagitis and nonerosive reflux disease (NERR comparison of epidemiologic, physiologic, and therap Atic characteristics. J Clin Gastroenterol. 2007 (2):131-137.

9. Arecci U, Bonina F, Bonina A, et al. Efficacy and Safety of a Natural Remedy for the Treatment of Gastroesophageal Reflux: A Double-Blinded Randomized-Controlled Study. Evid Based Complement Alternat Med. 2016;2016:2581461.

10. Henry MA. Diagnosis and management of gastroesophageal reflux disease. Arq Bras Cir Dig. 2014;27(3):210-5.

11. El-Serag H., Becher A., Jones R. Systematic review: persistent reflux symptoms on proton pump inhibitor therapy in primary care and community studies. Alimentary Pharmacology and Therapeutics. 2010;32(6):720-737. doi: 10.1111/j.13652036.2010.04406.x.

12. Perry K. A., Pham T. H., Spechler S. J., Hunter J. G., Melvin W. S., Velanovich V. 2014 SSAT state-of-the-art conference: advances in diagnosis and management of gastroesophageal reflux disease. Journal of Gastrointestinal Surgery. 2015;19(3):458466. doi: 10.1007/s11605-014-2724-9.

13. Galati E. M., Pergolizzi S., Miceli N., Monforte M. T., Tripodo M. $M$. Study on the increment of the production of gastric mucus in rats treated with Opuntia ficus indica (L.) Mill. cladodes. Journal of Ethnopharmacology. 2002;83(3):229-233. doi: 10.1016/s0378-8741(02)00243-x.

14. Galati E. M., Mondello M. R., Giuffrida D., et al. Chemical characterization and biological effects of sicilian Opuntia ficus indica (L.) Mill. fruit juice: antioxidant and antiulcerogenic activity. Journal of Agricultural and Food Chemistry. 2003;51(17):4903-4908. doi: 10.1021/jf030123d.

15. Trachtenberg S., Mayer A. M. Biophysical properties of Opuntia ficus-indica mucilage. Phytochemistry. 1980;21(12):2835-2843. doi: 10.1016/0031-9422(80)85052-7. 
16. Goulas V., Papoti V. T., Exarchou V., Tsimidou M. Z., Gerothanassis I. P. Contribution of flavonoids to the overall radical scavenging activity of olive (Olea europaea L.) leaf polar extracts. Journal of Agricultural and Food Chemistry. 2010;58(6):3303-3308. doi: 10.1021/jf903823x.

17. Herbella FA, Patti MG. Gastroesophageal reflux disease: From pathophysiology to treatment. World J Gastroenterol. 2010;16(30):3745-9.

18. Kahrilas PJ, Smith JA, Dicpinigaitis PV. A causal relationship between cough and gastroesophageal reflux disease (GERD) has been established: a pro/con debate. Lung. 2013;192(1):39-46.

19. Ates F, Vaezi MF. Insight Into the Relationship Between Gastroesophageal Reflux Disease and Asthma. Gastroenterol Hepatol (N Y). 2014;10(11):729-736.

20. Kerr M, Nall R. What Complementary and Alternative Medicines Work for Acid Reflux? Medically reviewed by Debra Rose Wilson, PhD, MSN, RN, IBCLC, AHN-BC, CHT. Healthline Web January 24, 2019.

21. Yeh AM, Golianu B. Integrative Treatment of Reflux and Functional Dyspepsia in Children. Children (Basel). 2014;1(2):119-33. Published 2014 Aug 18. doi:10.3390/children1020119

22. Hosseinkhani A, Lankarani KB, Mohagheghzadeh A, Long C, Pasalar M. An Evidence-based Review of Medicinal Herbs for the Treatment of Gastroesophageal Reflux Disease (GERD). Curr Drug Discov Technol. 2018;15(4):305-314. doi: 10.2174/1570163814666171010113517. PubMed PMID: 29032757.

23. Modlin I. M., Hunt R. H., Malfertheiner P., et al. Diagnosis and management of non-erosive reflux disease-The vevey NERD consensus group. Digestion. 2009;80(2):74-88. doi: 10.1159/000219365.

24. Mone I, Kraja B, Bregu A, Duraj V, Sadiku E, Hyska J Adherence to a predominantly Mediterranean di the risk of gastroesophageal reflux disease: a study in a South Eastern European populatj Jul 14. PubMed PMID: 26175057.

25. Gawron AJ, French DD, Pandolfing Howden CW. onomic evaluations of gastroesophage eflux d case medical management. Pharmacoeconom $24 ; 32$ (8) $745-58$

26. Benias PC, D'Souza L, Lan al. In. resection and plication AP) in thod calux: a pilot study. Endosc Int Op 2018

27. Gelardi M, Ciprandi G. on gastroesophageal reflux (GER) and laryngopharyngeal re $\quad(L P R)$ : new pragmatic insights in clinical practice. J Biol Regul h, meost Agents. 2018 JanFeb,;32(1 Suppl. 2):41-47. PubMed PMID: 29436209.

28. Web TRUHEALTH Medicine (May 16, 2018). How to naturally treat acid reflux at home?

29. Kiefer D, Cherney K. Herbs and Supplements for Acid Reflux (GERD). Reviewed by University of Illinois-Chicago, College of Medicine. Healthline March 22, 2016

30. Wong C. Remedies for Acid Reflux. Reviewed by Richard N. Fogoros, MD. Web Verywell health March 05, 2018

31. Deters A, Zippel J, Hellenbrand N, Pappai D, Possemeyer C, Hensel A. Aqueous extracts and polysaccharides from Marshmallow roots (Althea officinalis L.): cellular internalisation and stimulation of cell physiology of human epithelial cells in vitro. J Ethnopharmacol. 2010 Jan 8;127(1):62-9. doi: 10.1016/j.jep.2009.09.050. Epub 2009 Sep 30. PubMed PMID: 19799989.
32. Jirsa A. 3 Herbs To Heal Heartburn. Mindbodygreen Web. Available From: https://www.mindbodygreen.com/0-7555/3herbs-to-heal-heartburn.html

33. Di Pierro F, Gatti M, Rapacioli G, Ivaldi L. Outcomes in patients with nonerosive reflux disease treated with a proton pump inhibitor and alginic acid \pm glycyrrhetinic acid and anthocyanosides. Clin Exp Gastroenterol. 2013;6:27-33.

34. NaturalON Web. 12 Best Herbs for Acid Reflux

35. Muss C, Mosgoeller W, Endler T. Papaya preparation (Caricol ${ }^{\circledR}$ ) in digestive disorders. Neuro Endocrinol Lett. 2013;34(1):38-46. PubMed PMID: 23524622.

36. Aravind G, Bhowmik D, Duraivel S, Harish G. Traditional and Medicinal Uses of Carica papaya. Journal of Medicinal Plants Studies Year : 2013, Volume : 1 , Issue : 1, pp 7-15

37. DiSilvestro RA, Verbruggen MA, Offutt EJ. Anti-heartburn effects of a fenugreek fibe Jan;25(1):88-91. doi: 10 002/pth. 29. PubMed PMID: 20623611.

38. Pandian RS, Anur tha Ch Viswana an P. Gastroprotective effect of feny cek seeds (1, or ra foenum graecum) on experiment rastri acer in ràs. J Ethnopharmacol. 2002 Aug;81/393 abMed MID: 12127242.

39. Thay K, Mama i N Straus SE. Efficacy of turmeric in the tr ime of digesth disorders: a systematic review and metaanalysis pro col. Syst Rev. 2014;3:71. Published 2014 Jun 28. avi:10.1186/2 6-4053-3-71

0. Yadav $9 K$, Sah AK, Jha RK, Sah P, Shah DK. Turmeric (curcumin) remed sastroprotective action. Pharmacogn Rev. 2013. 13):42-6.

41. Schoen-Angerer T, Madeleyn R, Kiene H, Kienle GS, Vagedes Improvement of Asthma and Gastroesophageal Reflux Disease With Oral Pulvis stomachicus cum Belladonna, a Combination of Matricaria recutita, Atropa belladonna, Bismuth, and Antimonite: A Pediatric Case Report. Glob Adv Health Med. 2016;5(1):107-11.

42. Slikkerveer A, de Wolff FA. Pharmacokinetics and toxicity of bismuth compounds. Med Toxicol Adverse Drug Exp. 1989 SepOct;4(5):303-23. Review. PubMed PMID: 2682129.

43. Mastronarde JG. Is There a Relationship Between GERD and Asthma?. Gastroenterol Hepatol (N Y). 2012;8(6):401-3.

44. Whitfield KL, Shulman RJ. Treatment options for functional gastrointestinal disorders: from empiric to complementary approaches. Pediatr Ann. 2009;38(5):288-90, 292-4.

45. Lee AL, Goldstein RS. Gastroesophageal reflux disease in COPD links and risks. Int J Chron Obstruct Pulmon Dis. 2015;10:193549. Published 2015 Sep 14. doi:10.2147/COPD.S77562

46. Panahi $Y$, Khedmat $H$, Valizadegan $G$, Mohtashami R, Sahebkar A. Efficacy and safety of Aloe vera syrup for the treatment of gastroesophageal reflux disease: a pilot randomized positivecontrolled trial. J Tradit Chin Med. 2015 Dec;35(6):632-6. PubMed PMID: 26742306.

47. Baradaran A, Nasri H, Nematbakhsh M, Rafieian-Kopaei M. Antioxidant activity and preventive effect of aqueous leaf extract of Aloe Vera on gentamicin-induced nephrotoxicity in male Wistar rats. Clin Ter. 2014;165(1):7-11. doi: 10. 7471/CT. 2014. 1653. PubMed PMID

48. Guo X, Mei N. Aloe vera: A review of toxicity and adverse clinical effects. J Environ Sci Health C Environ Carcinog Ecotoxicol Rev. 2016 Apr 2;34(2):77-96. doi: 10.1080/10590501.2016.1166826. Review. PubMed PMID: 26986231. 
49. Rabe C, Musch A, Schirmacher P, Kruis W, Hoffmann R. Acute hepatitis induced by an Aloe vera preparation: a case report. World J Gastroenterol. 2005;11(2):303-4.

50. Feld L, Cifu AS. Management of Dyspepsia. JAMA. 2018;319(17):1816-1817. doi:10.1001/jama.2018.3435

51. Seyedmirzaei SM, Haghdoost AA, Afshari M, Dehghani A. Prevalence of dyspepsia and its associated factors among the adult population in southeast of iran in 2010. Iran Red Crescent Med J. 2014;16(11):e14757. Published 2014 Nov 1. doi:10.5812/ircmj.14757

52. Madisch A, Andresen V, Enck P, Labenz J, Frieling T, Schemann M. The Diagnosis and Treatment of Functional Dyspepsia. Dtsch Arztebl Int. 2018;115(13):222-232.

53. Ghoshal UC, Singh R, Chang FY, et al. Epidemiology of uninvestigated and functional dyspepsia in Asia: facts and fiction. J Neurogastroenterol Motil. 2011;17(3):235-44.

54. Nwokediuko SC, Ijoma U, Obienu O. Functional dyspepsia: subtypes, risk factors, and overlap with irritable bowel syndrome in a population of african patients. Gastroenterol Res Pract. 2012;2012:562393.

55. Tack J, Talley NJ, Camilleri M, et al. Functional gastroduodenal disorders. Gastroenterology. 2006;130(5):1466-1479.

56. Yamawaki H, Futagami S, Wakabayashi M, et al. Management of functional dyspepsia: state of the art and emerging therapies. Ther Adv Chronic Dis. 2017;9(1):23-32.

57. Haag S, Talley NJ, Holtmann G. Symptom patterns in functional dyspepsia and irritable bowel syndrome: relationship to disturbances in gastric emptying and response to a nutrient challenge in consulters and non-consulters. Gut 2004; 53 : 1445-1451.

58. Lacy BE, Weiser KT, Kennedy AT, et al. Functional dyspepsia: the economic impact to patients. Aliment Pharmacol Ther 2012. 38 170-177.

59. Aro P, Talley NJ, Agreus L, et al. Functional dysper quality of life in the adult population. Aliment 2011; 33: 1215-1224.

60. Moayyedi P, Mason J. Clinical and econ dyspepsia in the community. Gut 200

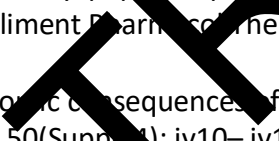
2002. 50(Suppl Y: iv10-iv12.

61. Talley NJ, Ford AC. Functional dysp osia. N Engl J M 2015; 373: 1853-1863.

62. Pittayanon R, Yuan $\mathrm{Y}$, Bollegala $N$ rna R, Lcy BE, Andrews $\mathrm{CN}$, Leontiadis $\mathrm{Gl}$, Moayy Pro etics f Functional Dyspepsia: A Systemat Revie and M Analysis of Randomized ControK ials. A anatroenterol. 2019 Jan 11. doi: 10.1038/s41395-0. 58-6. [Epub ahead of print] PubMed PMID: 30337705

63. Kinoshita $Y$, Ishimura N, Ishiha a S. Advantages and Disadvantages of Long-term Proton Pump Inhibitor Use. J Neurogastroenterol Motil. 2018;24(2):182-196.

64. de Bortoli N, Tolone S, Frazzoni M, et al. Gastroesophageal reflux disease, functional dyspepsia and irritable bowel syndrome: common overlapping gastrointestinal disorders. Ann Gastroenterol. 2018;31(6):639-648.

65. Swedish Council on Health Technology Assessment. Dyspepsia and Gastro-oesophageal Reflux: A Systematic Review (Summary and conclusions) [Internet]. Stockholm: Swedish Council on Health Technology Assessment (SBU); 2007 Oct. SBU Yellow Report No. 185. Available from: https://www.ncbi.nlm.nih.gov/books/NBK448002/

66. Simadibrata M. Dyspepsia and gastroesophageal reflux disease (GERD): is there any correlation? Acta Med Indones. 2009 Oct;41(4):222-7. Review. PubMed PMID: 20737754.
67. Chiarioni G, Pesce M, Fantin A, Sarnelli G. Complementary and alternative treatment in functional dyspepsia. United European Gastroenterol J. 2017;6(1):5-12.

68. Jaber N, Oudah M, Kowatli A, et al. Dietary and Lifestyle Factors Associated with Dyspepsia among Pre-clinical Medical Students in Ajman, United Arab Emirates. Cent Asian J Glob Health. 2016;5(1):192. Published 2016 Aug 15. doi:10.5195/cajgh.2016.192

69. Piessevaux H, De Winter B, Louis E, et al. Dyspeptic symptoms in the general population: a factor and cluster analysis of symptom groupings. Neurogastroenterol Motil 2009; 21: 378388.

70. Welen K, Faresjo A, Faresjo T. Functional dyspepsia affects women more than men in daily life: a case-control study in primary care. Gened Med 2008; 5: 62-73.

71. Raveendra KR, Jayachand iyasa V, Sushma KR, Allan JJ, Goudar KS, Shivaprasar IN, Venk eshwarlu K, Geetharani P, Sushma G, Agarwal A. Extract of lycyrrhiza glabra (GutGard) Allevir S Sym, 'ms of 'nctional Dyspepsia: A Randomized, ouble-Blind, o-Controlled Study. Evid Based Comk ment rernat Mrd. 2012;2012:216970. doi: 10.1155 012 701 . Ep 2011 Jun 16. PubMed PMID: 2174 93; PubMl Ce al PMCID: PMC3123991.

72. M tas mi R, Huse r HF, Heydari M, Amini M, Sadeqhi Z, Ghaznavi A, Yehrzadi S. Efficacy and safety of honey based rormulation o. ligella sativa seed oil in functional dyspepsia: A doubleplind randomized controlled clinical trial. J Ethnop armacol. 2015 Dec 4;175:147-52. doi: 10.10 /j.jep.2015.09.022. Epub 2015 Sep 18. PubMed PMID: 6381.

Piero Sestili, Tariq Ismail, Cinzia Calcabrini, Michele Guescini, Elena Catanzaro, Eleonora Turrini, Anam Layla, Saeed Akhtar \& Carmela Fimognari (2018) The potential effects of Ocimum basilicum on health: a review of pharmacological and toxicological studies, Expert Opinion on Drug Metabolism \& Toxicology, 14:7, 679-692, DOI: 10.1080/17425255.2018.1484450

74. Rafieian K, Hosseini-Asl K. Effects of Ocimum basilicum on functional dyspepsia: a double-blind placebo-controlled study. IJMS. 2005;30:134-7

75. Chawla YK, Dubey P, Singh R, Nundy S, Tandon BN. Treatment of dyspepsia with Amalaki (Emblica officinalis Linn.)--an Ayurvedic drug. Indian J Med Res. 1982;76 Suppl:95-8.

76. Grover HS, Deswal $H$, Singh $Y$, Bhardwaj A. Therapeutic effects of amla in medicine and dentistry: A review. J Oral Res Rev 2015;7:65-8

77. Usharani P, Fatima N, Muralidhar N. Effects of Phyllanthus emblica extract on endothelial dysfunction and biomarkers of oxidative stress in patients with type 2 diabetes mellitus: a randomized, double-blind, controlled study. Diabetes Metab Syndr Obes. 2013;6:275-84. Published 2013 Jul 26. doi:10.2147/DMSO.S46341

78. Dabos KJ, Sfika E, Vlatta LJ, Frantzi D, Amygdalos GI, Giannikopoulos $\mathrm{G}$. Is Chios mastic gum effective in the treatment of functional dyspepsia? A prospective randomised double-blind placebo controlled trial. J Ethnopharmacol. 2010;127(2):205-9. doi: 10.1016/j.jep.2009.11.021.

79. Maliheh Safavi, Mohammadreza Shams-Ardakani \& Alireza Foroumadi (2015) Medicinal plants in the treatment of Helicobacter pylori infections, Pharmaceutical Biology, 53:7, 939-960, DOI: 10.3109/13880209.2014.952837 
80. de Lima RMT, Dos Reis AC, de Menezes APM, Santos JVO, Filho JWGO, Ferreira JRO, de Alencar MVOB, da Mata AMOF, Khan IN, Islam A, Uddin SJ, Ali ES, Islam MT, Tripathi S, Mishra SK, Mubarak MS, Melo-Cavalcante AAC. Protective and therapeutic potential of ginger (Zingiber officinale) extract and [6]-gingerol in cancer: A comprehensive review. Phytother Res. 2018 Oct;32(10):1885-1907. doi: 10.1002/ptr.6134. Epub 2018 Jul 16. Review. PubMed PMID: 30009484.

81. Haniadka R, Saldanha E, Sunita V, Palatty PL, Fayad R, Baliga $M S$. A review of the gastroprotective effects of ginger (Zingiber officinale Roscoe). Food Funct. 2013 Jun;4(6):845-55. doi: 10.1039/c3fo30337c. Epub 2013 Apr 24. Review. PubMed PMID: 23612703.

82. Hu ML, Rayner CK, Wu KL, et al. Effect of ginger on gastric motility and symptoms of functional dyspepsia. World J Gastroenterol. 2011;17(1):105-10.

83. Bode AM, Dong Z. The Amazing and Mighty Ginger. In: Benzie IFF, Wachtel-Galor S, editors. Herbal Medicine: Biomolecular and Clinical Aspects. 2nd edition. Boca Raton (FL): CRC Press/Taylor \& Francis; 2011. Chapter 7. Available from: https://www.ncbi.nlm.nih.gov/books/NBK92775/

84. MacFarlane B. Management of gastroesophageal reflux disease in adults: a pharmacist's perspective. Integr Pharm Res Pract. 2018;7:41-52. Published 2018 Jun 5. doi:10.2147/IPRP.S142932

85. Sanati S, Razavi BM, Hosseinzadeh $\mathrm{H}$. A review of the effects of Capsicum annuum $\mathrm{L}$. and its constituent, capsaicin, in metabolic syndrome. Iran J Basic Med Sci. 2018;21(5):439-448.

86. Pasalar M, Nimrouzi M, Choopani R, et al. Functional dyspepsia: A new approach from traditional Persian medicine. Avicenna J Phytomed. 2016;6(2):165-74.

87. Forootan M, Bagheri N, Darvishi M. Chronic constipation: A review of literature. Medicine (Baltimore). 2018;97(20)

88. Diaz S, Mendez MD. Constipation. [Updated $2018 \mathrm{~N}$ StatPearls [Internet]. Treasure Island (FL): StatPea 2018 Jan-. Available from: https://www.ncbi.nlm.nih.gov/books/NBK5 291/

89. Tack J, Müller-Lissner S, Stanghellini V, treatment of chronic constipationNeurogastroenterol Motil 2011;23 7-710.

90. De Giorgio R, Ruggeri E, Stangh ani V, E ebi LH, Bazzoli F, Chiarioni G. Chronic constipation th elderly primer for the gastroenterologist. BMC 2015 5:130. Published 2015 Oct 14. doi:10.11

91. Higgins PD, Johanso Epid hino of constipation in North America: a systematic N. Am J Gastroenterol. 2004;99:750-9. doi: 10.11 Vj.1572-0241.2004.04114.x.

92. Bharucha AE, Pemberton JH, cke GR., III American Gastroenterological Association technical review on constipation. Am Gastroenterol Assoc Gastroenterol. 2013;144:218-38.

93. Fragakis A, Zhou J, Mannan H, Ho V. Association between Drug Usage and Constipation in the Elderly Population of Greater Western Sydney Australia. Int J Environ Res Public Health. 2018;15(2):226. Published 2018 Jan 29.

doi:10.3390/ijerph15020226.

94. Sandler R, Drossman DA. Bowel habits in young adults not seeking health care. Dig Dis Sci. 1987;32:841-5.

95. Huang $L$, Jiang $H$, Zhu $M$, et al. Prevalence and Risk Factors of Chronic Constipation Among Women Aged 50 Years and Older in Shanghai, China. Med Sci Monit. 2017;23:2660-2667. Published 2017 May 31. doi:10.12659/MSM.904040.
96. Sanchez MI, Bercik P. Epidemiology and burden of chronic constipation. Can J Gastroenterol. 2011;25 Suppl B(Suppl B):11B-15B.

97. Colopast Web.The Cost of Constipation report. Available From: https://www.coloplast.co.uk/Global/UK/Continence/Cost of C onstipation Report FINAL.pdf

98. WebMD. Vitamins \& Supplements. CASCARA SAGRADA. Available From: https://www.webmd.com/vitamins/ai/ingredientmono773/cascara-sagrada

99. Portalatin M, Winstead N. Medical management of constipation. Clin Colon Rectal Surg. 2012;25(1):12-9.

100. Liu LW. Chronic constipation: current treatment options. Can J Gastroenterol. 2011;25 Suppl B(Suppl B):22B-28B.

101. Nguyen NQ, Chapman M, Fraser RJ, et al. Prokinetic therapy for feed intolerance in critical one drug or two? Crit Care Med 35: 2561-2567, 2

102. Shimizu K, Kageyama Ogura H, Y mada T, Shimazu T. Effects of Rhubarb on In stinal. smotilit In Critically III Patients. Intern Med.

103. Chen DC, W T. L chanisms of therapeutic effects of rhubarb gu sin seps Chin J Traumatol 12: 365-369, 2009

104. liz a $\mathrm{N}$, amamoto Constipation and herbal medicine. Front Pharmacol. 015;6:73. Published 2015 Apr 8. avi:10.3389/1 ar.2015.00073

05. McDerpott A. 5 Herbal Remedies for Constipation. Reviewed by Deb Rose Wilson, PhD, MSN, RN, IBCLC, AHN-BC, CHT. Healt he Web November 21, 2017.

106. Hova-Sanchez A, Gasior AC, Toocheck N, Weaver L, Wood RJ, Reck CA, Wagner A, Hoover E, Gagnon R, Jaggers J, Maloof T, Nash O, Williams C, Levitt MA. Are Senna based laxatives safe when used as long term treatment for constipation in children? J Pediatr Surg. 2018 Apr;53(4):722-727. doi: 10.1016/j.jpedsurg.2018.01.002. Epub 2018 Jan 31. Review. PubMed PMID: 29429768.

107. Trottier M, Erebara A, Bozzo P. Treating constipation during pregnancy. Can Fam Physician. 2012;58(8):836-8.

108. John L, Shantakumari N. Herbal Medicines Use During Pregnancy: A Review from the Middle East. Oman Med J. 2015;30(4):229-36.

109. Since herbal medicines are a part of traditional medicine, they are not included in the FDA pregnancy categories giving a false impression of safety. The whole extracts of these herbal drugs contain numerous active molecules that could elicit adverse effects including teratogenicity.

110. Marcus DM, Snodgrass WR. Do no harm: avoidance of herbal medicines during pregnancy. Obstet Gynecol 2005. May;105(5 Pt 1):1119-1122. 10.1097/01.AOG.0000158858.79134.ea

111. Cuzzolin L, Benoni G. Safety issues of phytomedicine in pregnancy and pediatrics. In: Ramawat KJ (ed). Herbal Drugs: Ethnomedicine to Modern Medicine. Springer-Verlag Berlin Heidelberg 2009: 382.

112. Tiran $D$. The use of herbs by pregnant and childbearing women: a risk-benefit assessment. Complement Ther Nurs Midwifery 2003. Nov;9(4):176-181. 10.1016/S1353-6117(03)00045-3.

113. Igarashi $\mathrm{M}, \mathrm{Nakae} \mathrm{H}$, Matsuoka $\mathrm{T}$, et al Alteration in the gastric microbiota and its restoration by probiotics in patients with functional dyspepsia BMJ Open Gastroenterology 2017;4:e000144. doi: 10.1136/bmjgast-2017-000144. 
114. Tabbers MM, Dilorenzo C, Berger MY, Faure C, Langendam MW, Nurko S, Staiano A, Vandenplas Y, Benninga MA. Evaluation and treatment of functional constipation in infants and children: evidence-based recommendations from ESPGHAN and NASPGHAN. J Pediatr Gastroenterol Nutr. 2014;58:265-281. doi: 10.1097/MPG.0000000000000266.

115. Alammar N, Stein E. Irritable Bowel Syndrome: What Treatments Really Work. Med Clin North Am. 2019 Jan;103(1):137-152. doi: 10.1016/j.mcna.2018.08.006. Review. PubMed PMID: 30466670.

116. Garcia-Etxebarria K, Zheng T, Bonfiglio F, Bujanda L, Dlugosz A, Lindberg G, Schmidt PT, Karling P, Ohlsson B, Simren M, Walter S, Nardone G, Cuomo R, Usai-Satta P, Galeazzi F, Neri M, Portincasa P, Bellini M, Barbara G, Jonkers D, Eswaran S, Chey WD, Kashyap P, Chang L, Mayer EA, Wouters MM, Boeckxstaens G, Camilleri M, Franke A, D'Amato M. Increased Prevalence of Rare Sucrase-isomaltase Pathogenic Variants in Irritable Bowel Syndrome Patients. Clin Gastroenterol Hepatol. 2018 Oct;16(10):1673-1676. doi: 10.1016/j.cgh.2018.01.047. Epub 2018 Feb 21. PubMed PMID: 29408290; PubMed Central PMCID: PMC6103908.

117. Lacy B, Ayyagari R, Guerin A, Lopez A, Shi S, Luo M. Factors associated with more frequent diagnostic tests and procedures in patients with irritable bowel syndrome. Therap Adv Gastroenterol. 2019;12:1756284818818326. Published 2019 Jan 1. doi:10.1177/1756284818818326.

118. Borghini R, Donato $G$, Alvaro D, Picarelli A. New insights in IBSlike disorders: Pandora's box has been opened; a review. Gastroenterol Hepatol Bed Bench. 2017;10(2):79-89.

119. Wald A, Talley N, Grover S. Treatment of irritable bowel syndrome in adults. Available From: https://www.uptodate.com/contents/treatment-of-irrit_ralebowel-syndrome-inadults?source=search result\&search=irritable $\% 20$ owel\% svin drome\&selectedTitle $=1 \sim 150$

120. IBS GLOBAL IMPACT REPORT 2018. BS GLOP IMPAC, FPORT 2018 With significant contribution from Society Uncovering the true burden gejrritable of vel syndrome (IBS) on people's lives. Available https://www.badgut.org/wp-co Impact-Report.pdf

121. Su AM, Shih W, Presson symptoms in irritable terol pattern. Neurogastr terol 2014Jan;26(1):36-45. doi: 10.1111/nmo.12220. Ê 013 Aug 29. PubMed PMID: 23991913; PubMed Centro. YMCID: PMC3865067.

122. Cañón M, Ruiz AJ, Rondón M, Mvarado J. Prevalence of irritable bowel syndrome and health-related quality of life in adults aged 18 to 30 years in a Colombian University: an electronic survey. Ann Gastroenterol. 2016;30(1):67-75.

123. Abdul Rani R, Raja Ali RA, Lee YY. Irritable bowel syndrome and inflammatory bowel disease overlap syndrome: pieces of the puzzle are falling into place. Intest Res. 2016;14(4):297-304.

124. Goldbaum E. IBS patients obtain robust, enduring relief from home-based treatment program. ScienceDaily Web April 23, 2018.

125. Bahrami HR, Hamedi S, Salari R, Noras M. Herbal Medicines for the Management of Irritable Bowel Syndrome: A Systematic Review. Electron Physician. 2016;8(8):2719-2725. Published 2016 Aug 25. doi:10.19082/2719.
126. Rahimi R, Abdollahi M. Herbal medicines for the management of irritable bowel syndrome: a comprehensive review. World J Gastroenterol. 2012;18(7):589-600.

127. Grundmann O, Yoon SL. Complementary and alternative medicines in irritable bowel syndrome: an integrative view. World J Gastroenterol. 2014;20(2):346-62.

128. US FDA Admin Web. Zelnorm (tegaserod maleate) Information. Available From: https://www.fda.gov/Drugs/DrugSafety/ucm103223.htm

129. KEY POINT. Tegaserod withdrawn from U.S. market. APhA Drug Info Online Web April 1, 2007.

130. WHO Web. Alosetron - withdrawn: severe adverse reactions. Available From: http://apps.who.int/medicinedocs/en/d/Jh1466e/2.3.html

131. National Collaborating Centre for Nursing and Supportive Care (UK). Irritable Bowel Synd Adults: Diagnosis and Management of Irritab' Bowel S, drome in Primary Care [Internet]. London: Ro College of Jursing (UK); 2008 Feb. (NICE Clinical Gy clines, 61.) 7 Biet and lifestyle. Available from: https:// ww.nchi.nlm ib ov/books/NBK51960/

132. Hawrelak J Myers . Effects of two natural medicine formula ons o cable b cel syndrome symptoms: a pilot stud Altern Co. Jep tht Med. 20100ct;16(10):1065-71. doi: 1C 08s, cm.2009.0 00. PubMed PMID: 20954962.

133. Walker AP, iddleton RW, Petrowicz O. Artichoke leaf extract reduces symp nsof irritable bowel syndrome in a postmarketing surveillance study. PhytotherRes. 2001 Feb;15(1):5861. Pui hed PMID: 11180525.

Villun en M, Aznar S, Pakkenberg B, Jess T, Brudek T. mmatory bowel disease increases the risk of Parkinson's disease: a Danish nationwide cohort study 1977-2014. Gut. 2019 Jan;68(1):18-24. doi: 10.1136/gutjnl-2017-315666. Epub 2018 May 21. PubMed PMID: 29785965.

135. Kreuter R, Wankell M, Ahlenstiel G, Hebbard L. The role of obesity in inflammatory bowel disease. Biochim Biophys Acta Mol Basis Dis. 2019 Jan;1865(1):63-72. doi: 10.1016/j.bbadis.2018.10.020. Epub 2018 Oct 22. Review. PubMed PMID: 30352258.

136. Christensen B. Inflammatory bowel disease and sexual dysfunction. Gastroenterol Hepatol (N Y). 2014;10(1):53-5.

137. de Vries JHM, Dijkhuizen M, Tap P, Witteman BJM. Patient's Dietary Beliefs and Behaviours in Inflammatory Bowel Disease. Dig Dis. 2019;37(2):131-139. doi: 10.1159/000494022. Epub 2018 Nov 2. PubMed PMID: 30391940.

138. Volk N, Siegel CA. Defining Failure of Medical Therapy for Inflammatory Bowel Disease. Inflamm Bowel Dis. 2019 Jan 1;25(1):74-77. doi: 10.1093/ibd/izy238. PubMed PMID: 30016434.

139. Naviglio S, Lacorte D, Lucafò M, Cifù A, Favretto D, Cuzzoni E, Silvestri T, Pozzi Mucelli M, Radillo O, Decorti G, Fabris M, Bramuzzo M, Taddio A, Stocco G, Alvisi P, Ventura A, Martelossi $S$. Causes of Treatment Failure in Children With Inflammatory Bowel Disease Treated With Infliximab: A Pharmacokinetic Study. J Pediatr Gastroenterol Nutr. 2019 Jan;68(1):37-44. doi: 10.1097/MPG.0000000000002112. PubMed PMID: 30211845. 
140. Shen B, Kochhar G, Navaneethan U, Liu X, Farraye FA, GonzalezLama Y, Bruining D, Pardi DS, Lukas M, Bortlik M, Wu K, Sood A, Schwartz DA, Sandborn WJ; Global Interventional Inflammatory Bowel Disease Group. Role of interventional inflammatory bowel disease in the era of biologic therapy: a position statement from the Global Interventional IBD Group. Gastrointest Endosc. 2019 Feb;89(2):215-237. doi: 10.1016/j.gie.2018.09.045. Epub 2018 Oct 24. Review. PubMed PMID: 30365985.

141. Lee HS, Park SK, Park DI. Novel treatments for inflammatory bowel disease. Korean J Intern Med. 2017;33(1):20-27.

142. Ford AC, Peyrin-Biroulet L. Opportunistic infections with antitumor necrosis factor- $\alpha$ therapy in inflammatory bowel disease: meta-analysis of randomized controlled trials. Am J Gastroenterol. 2013;108:1268-1276.

143. Walsh AJ, Weltman M, Burger D, et al. Implementing guidelines on the prevention of opportunistic infections in inflammatory bowel disease. J Crohns Colitis. 2013;7:e449-e456.

144. Wilhelm SM, Love BL. Management of patients with inflammatory bowel disease: current and future treatments. Clinical Pharmacist, Web The Pharmaceutical Journal 1 February 2017.

145. Feagan BG, Sandborn WJ, Colombel JF, et al. Incidence of Arthritis/Arthralgia in Inflammatory Bowel Disease with Longterm Vedolizumab Treatment: Post Hoc Analyses of the GEMINI Trials. J Crohns Colitis. 2018;13(1):50-57.

146. Adamiak T, Walkiewicz-Jedrzejczak D, Fish D, et al. Incidence, clinical characteristics, and natural history of pediatric IBD in Wisconsin: a population-based epidemiological study. Inflamm Bowel Dis. 2013;19(6):1218-23.

147. Burnett-Hartman AN, Hua X, Rue TC, Golchin N, Kessler L, Rowhani-Rahbar A. Risk interval analysis of emergency visits following colonoscopy in patients with inflamn bowel disease. PLoS One. 2019;14(1):e0210262. P Jan 9. doi:10.1371/journal.pone.0210262.

148. Ananthakrishnan AN, Bernstein CN, Iliopou D, Macp, rson A, Neurath MF, Ali RAR, Vavricka SR, Fio triggers in IBD: a review of progress and Reviews Gastroenterology \& Hepa rogy volume 1b, ages 3949 (2018).

149. Triantafyllidi A, Xanthos T, Papa A Mantafilidis JK. Herbal and plant therapy in patie Ann Gastroenterol. 201, 28(2) 10-22

150. Ben-Arye E, Goldin E Vengr Stamper A, Kohn R, Berry $E$. Wheat grass juice in eatment of active distal ulcerative colitis: a randomized doub, blind placebo-controlled trial. Scand J Gastroenterol. 2002; .444-449.

151. Tang T., Targan S. R., Li Z.-S., Xu C., Byers V. S., Sandborn W. J. Randomised clinical trial: herbal extract HMPL-004 in active ulcerative colitis - a double-blind comparison with sustained release mesalazine. Alimentary Pharmacology and Therapeutics. 2011;33(2):194-202. doi: 10.1111/j.13652036.2010.04515.x.

152. Gupta I, Parihar A, Malhotra P, et al. Effects of gum resin of Boswellia serrata in patients with chronic colitis. Planta Med. 2001;67:391-395.

153. Omer B., Krebs S., Omer H., Noor T. O. Steroid-sparing effect of wormwood (Artemisia absinthium) in Crohn's disease: a doubleblind placebo-controlled study. Phytomedicine. 2007;14(23):87-95. doi: 10.1016/j.phymed.2007.01.001.
154. Sun J, Shen X, Dong J, Wang H, Zuo L, Zhao J, Zhu W, Li Y, Gong $\mathrm{J}$, Li J. Tripterygium wilfordii Hook F as Maintenance Treatment for Crohn's Disease. Am J Med Sci. 2015 Nov;350(5):345-51. doi: 10.1097/MAJ.0000000000000591. PubMed PMID: 26473333

155. Ng SC, Lam YT, Tsoi KK, Chan FK, Sung JJ, Wu JC. Systematic review: the efficacy of herbal therapy in inflammatory bowel disease. Aliment Pharmacol Ther. 2013 Oct;38(8):854-63. doi: 10.1111/apt.12464. Epub 2013 Aug 25. Review. PubMed PMID: 23981095.

156. Athasit Kijmanawat, Panyu Panburana, Sirimon Reutrakul and Chayada Tangshewinsirikul, Effects of probiotic supplements on insulin resistance in gestational diabetes mellitus: A doubleblind randomized controlled trial, Journal of Diabetes Investigation, 10, 1, (163-170), (2018).

157. Holzapfel WH, Haberer $P$ Schillinger $U$, Huis in 't Veld JHJ. Overview of gut fle and pro ptics. Int J Food Microbiol 1998;41: 85-101

158. Gorbach SL. Lact acid bo eria an human health. Ann Med 1990;22: 37

159. Jonkers D, skbrü ser R. Proviotics and inflammatory bowel disease $R$ So d. 2003 (4):167-71.

160. Plaz? az J, Ruiz- edz s, Vilchez-Padial LM, Gil A. Evidence of th Ant flammato, Effects of Probiotics and Synbiotics in Intestinal Q onic Diseases. Nutrients. 2017;9(6):555. Published Zu17 May 28. ji:10.3390/nu9060555.

61. Lee EJ Jee YJ, Park JH. Usefulness of Ultrasonography in the Diagng s of Peptic Ulcer Disease in Children. Pediatr Gastr nterol Hepatol Nutr. 2019;22(1):57-62.

162. Chen TP, Wei CY, Chang YC. Association between Peptic Ulcer Disease and Periodontitis: A Nationwide Population-Based Case-Control Study in Taiwan. Int J Environ Res Public Health. 2018;15(5):912. Published 2018 May 4. doi:10.3390/ijerph15050912.

163. Malik TF, Singh K. Peptic Ulcer Disease. [Updated 2018 Dec 4]. In: StatPearls [Internet]. Treasure Island (FL): StatPearls Publishing; 2018 Jan-. Available from: https://www.ncbi.nlm.nih.gov/books/NBK534792/

164. Lanas A, Chan FKL. Peptic ulcer disease. Lancet. 2017 Aug 05;390(10094):613-624.

165. Akeel M, Elmakki E, Shehata A, et al. Prevalence and factors associated with $\mathrm{H}$. pylori infection in Saudi patients with dyspepsia. Electron Physician. 2018;10(9):7279-7286. Published 2018 Sep 9. doi:10.19082/7279.

166. Vomero ND, Colpo E. Nutritional care in peptic ulcer. Arq Bras Cir Dig. 2014;27(4):298-302.

167. Lafortuna CL, Agosti F, Marinone PG, Marazzi N, Sartorio A. The relationship between body composition and muscle power output in men and women with obesity. J Endocrinol Invest. 2004;27:854-861.

168. Sayehmiri K, Abangah G, Kalvandi G, Tavan H, Aazami S. Prevalence of peptic ulcer in Iran: Systematic review and metaanalysis methods. J Res Med Sci. 2018;23:8. Published 2018 Jan 29. doi:10.4103/jrms.JRMS_1035_16.

169. Narayanan M, Reddy KM, Marsicano E. Peptic Ulcer Disease and Helicobacter pylori infection. Mo Med. 2018;115(3):219-224.

170. Mayank K, Gunja S, Pratap SM. Pathophysiological status and nutritional therapy of peptic ulcer: An update. Year : 2017 | Volume: 2 | Issue Number: 3 | Page: 76-86. 
171. Mattos LL, Martins IS. Dietary fiber consumption in an adult population. Rev Saude Publica. 2000 Feb; 34(1):50-5.

172. Vomero ND, Colpo E. Nutritional care in peptic ulcer. Arq Bras Cir Dig. 2014;27(4):298-302.

173. Cheng Y, Macera CA, Davis DR, Blair SN. Physical activity and peptic ulcers. Does physical activity reduce the risk of developing peptic ulcers?. West J Med. 2000;173(2):101-7.

174. Albaqawi ASB, El-Fetoh NMA, Alanazi RFA, et al. Profile of peptic ulcer disease and its risk factors in Arar, Northern Saudi Arabia. Electron Physician. 2017;9(11):5740-5745. Published 2017 Nov 25. doi:10.19082/5740.

175. Levenstein S, Kaplan GA, Smith M. Sociodemographic characteristics, lifestressors, and peptic ulcer. A prospective study. J Clin Gastroenterol. 19950ct;21(3):185-92. PubMed PMID: 8648050.

176. Shephard RJ. Peptic Ulcer and Exercise. Sports Med. 2017 Jan;47(1):33-40. doi: 10.1007/s40279-016-0563-4. Review. PubMed PMID: 27282926.

177. Vimala G, Gricilda Shoba F. A review on antiulcer activity of few Indian medicinal plants. Int J Microbiol. 2014;2014:519590.

178. Nadkarni's KM. Indian Materia Medica, Volume 1. Mumbai, India: Popular Prakashan; 1976.

179. Díaz-de-Cerio E, Verardo V, Gómez-Caravaca AM, FernándezGutiérrez A, Segura-Carretero A. Health Effects of Psidium guajava L. Leaves: An Overview of the Last Decade. Int J Mol Sci. 2017;18(4):897. Published 2017 Apr 24. doi:10.3390/ijms18040897.

180. Ilavarasan JR, Monideen S, Vijayalakshmi M. Antiulcer activity of Aegle marmelos . Ancient Science of Life. 2002;21(4):23-26.

181. Park JJ. The Garlic Preparation as an Alternative Way for Gastroprotection: From Bench to Clinic. Gut Liver. 2016;10(3):321-2.

182. El-Ashmawy NE, Khedr EG, El-Bahrawy HA, Selim H Gastroprotective effect of garlic in indomethacin gastric ulcer in rats. Nutrition. 2016 Jul-Aug;32 10.1016/j.nut.2016.01.010. Epub 2016 Jan PubMea MID: 27158056.

183. Gadekar R, Singour PK, Chaurasiya PKAPawar RS, til UK. A

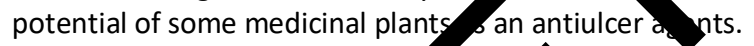
Pharmacogn Rev. 2010;4(8):13f

184. Alzohairy MA. Therapeutics Role A dirachtrindica (Neem) and Their Active Constityr Dis ses Pr ention and Treatment. Evid Based omple pent AN at Med. 2016;2016:7382506.

185. Zakaria ZA, Abdul Hisan Rofiee MIS, Norhafizah M, Somchit MN, Teh LK, Salleh MZ. In $\mathrm{o}$ antiulcer activity of the aqueous extract of Bauhinia purpurea vaf. J Ethnopharmacol. $2011 \mathrm{Sep}$ 2;137(2):1047-54. doi: 10.1016/j.jep.2011.07.038. Epub 2011 Jul 23. PubMed PMID: 21802502.

186. Sharifi-Rad M, Fokou PVT, Sharopov F, et al. Antiulcer Agents: From Plant Extracts to Phytochemicals in Healing Promotion. Molecules. 2018;23(7):1751. Published 2018 Jul 17. doi:10.3390/molecules23071751.

187. Farzaei MH, Abdollahi M, Rahimi R. Role of dietary polyphenols in the management of peptic ulcer. World J Gastroenterol. 2015;21(21):6499-517.

188. Rahnama M, Mehrabani D, Japoni S, Edjtehadi M, Saberi Firoozi $M$. The healing effect of licorice (Glycyrrhiza glabra) on Helicobacter pylori infected peptic ulcers. J Res Med Sci. 2013;18(6):532-3.
189. Almasaudi SB, Abbas AT, Al-Hindi RR, et al. Manuka Honey Exerts Antioxidant and Anti-Inflammatory Activities That Promote Healing of Acetic Acid-Induced Gastric Ulcer in Rats. Evid Based Complement Alternat Med. 2017;2017:5413917.

190. Markowiak P, Śliżewska K. Effects of Probiotics, Prebiotics, and Synbiotics on Human Health. Nutrients. 2017;9(9):1021. Published 2017 Sep 15. doi:10.3390/nu9091021.

191. Khoder G, Al-Menhali AA, Al-Yassir F, Karam SM. Potential role of probiotics in the management of gastric ulcer. Exp Ther Med. 2016;12(1):3-17.

192. Jorge M.B. Vítor, Filipa F. Vale; Alternative therapies for Helicobacter pylori: probiotics and phytomedicine, FEMS Immunology \& Medical Microbiology, Volume 63, Issue 2, 1 November 2011, Pages 153-164, https://doi.org/10.1111/j.1574-695X.2011.00865.x 